\title{
Evaluation of a Dual Beam Laser Doppler Displacement Meter Retrofitted to a Coordinate Measuring Machine
}

Federal Manufacturing \& Technologies

S. J. Ramsdale and

R. A. Hanshaw

KCP-613-5928

Published May 1997

Final Report

S. J. Ramsdale, Project Leader

Approved for public release; distribution is unlimited.

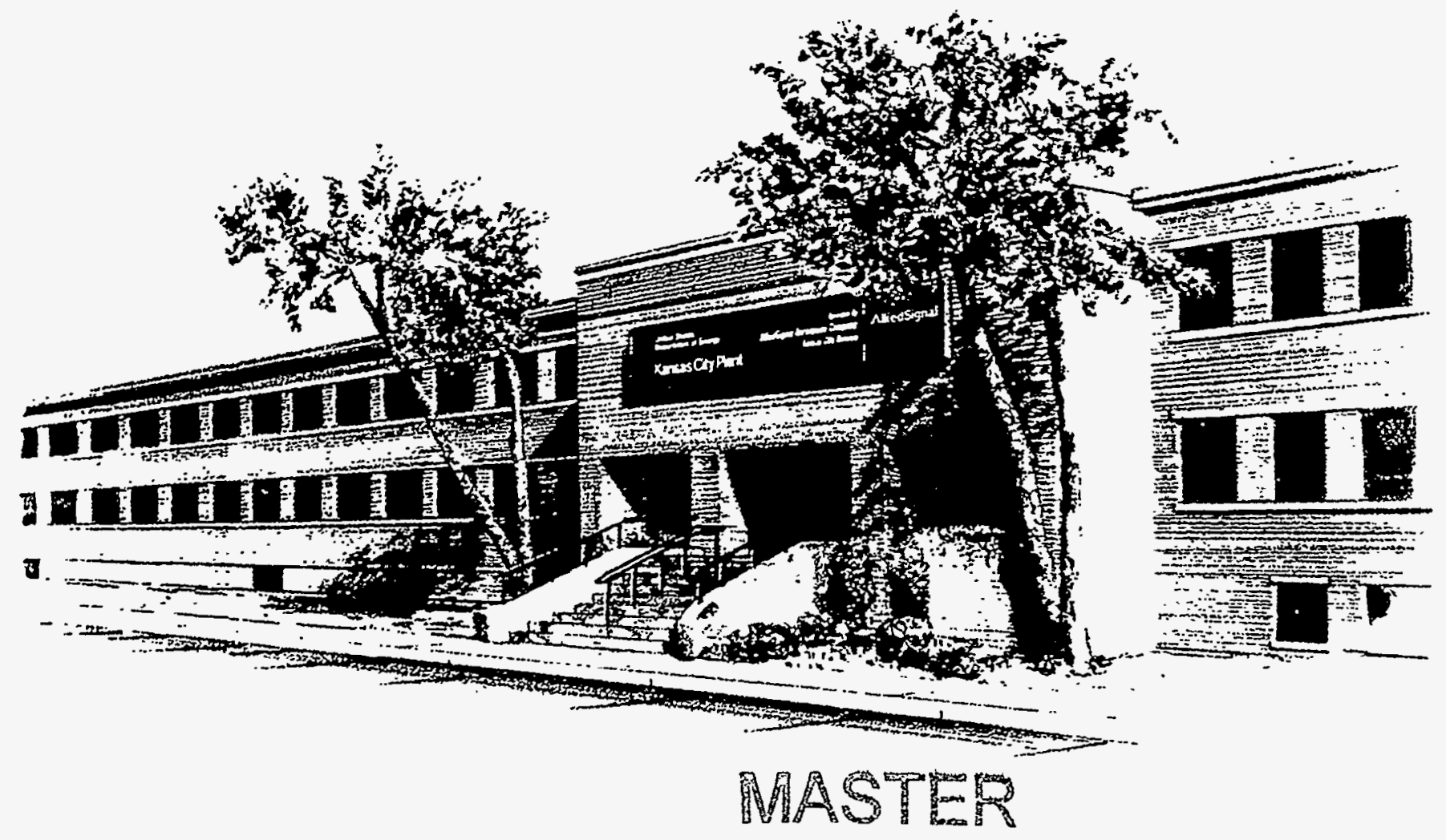




\section{DISCLAIMIER}

Portions of this document may be illegible in electronic image products. Images are produced from the best available original document. 


\section{DISCLAIMER}

This report was prepared as an account of work sponsored by an agency of the United States Government. Neither the United States Government nor any agency thereof, nor any of their employees, makes any warranty, express or implied, or assumes any legal liability or responsibility for the accuracy, completeness, or usefulness of any information, apparatus, product, or process disclosed, or represents that its use would not infringe privately owned rights. Reference herein to any specific commercial product, process, or service by trade names, trademark, manufacturer, or otherwise, does not necessarily constitute or imply its endorsement, recommendation, or favoring by the United States Government or any agency thereof. The views and opinions of authors expressed herein do not necessarily state or reflect those of the United States Government or any agency thereof.

All data prepared, analyzed and presented has been developed in a specific context of work and was prepared for internal evaluation and use pursuant to that work authorized under the referenced contract. Reference herein to any specific commercial product, process or service by trade name, trademark, manufacturer, or otherwise, does not necessarily constitute or imply its endorsement, recommendation, or favoring by the United States Government, any agency thereof or AlliedSignal Inc.

Printed in the United States of America.

This report has been reproduced from the best available copy.

Available to DOE and DOE contractors from the Office of Scientific and Technical Information, P. O. Box 62, Oak Ridge, Tennessee 37831; prices available from (615) 576-8401, FTS 626-8401.

Available to the public from the National Technical Information Service, U. S. Department of Commerce, 5285 Port Royal Rd., Springfield, Virginia 22161.

AlliedSignal Inc. Federal Manufacturing \& Technologies P. O. Box 419159 Kansas City, Missouri 64141-6159 
KCP-613-5928

Distribution Category UC-706

Approved for public release; distribution is unlimited.

\section{EVALUATION OF A DUAL BEAM LASER DOPPLER}

DISPLACEMENT METER RETROFITTED

TO A COORDINATE MEASURING MACHINE

S. J. Ramsdale and

R. A. Hanshaw

Published May 1997

Final Report

S. J. Ramsdale, Project Leader

Project Team:

R. A. Hanshaw

C. Wang, Optodyne, Inc. 


\section{Contents}

Section

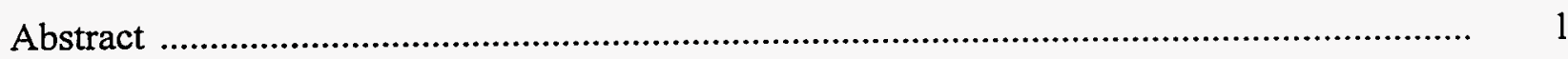

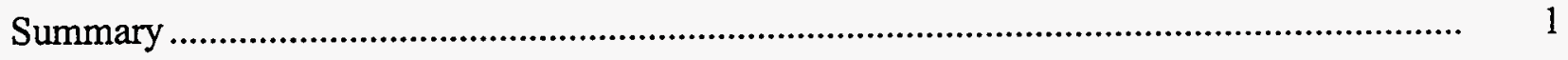

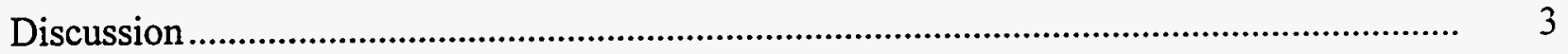

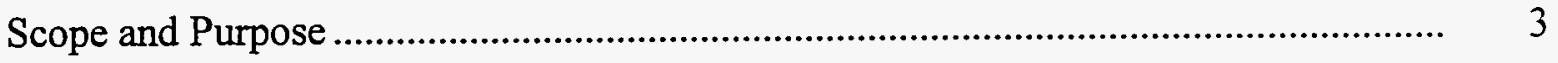

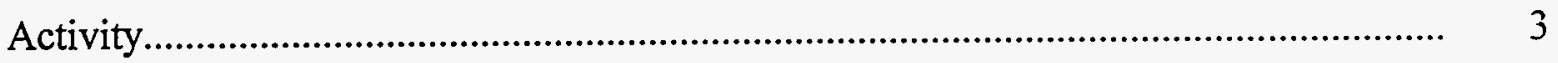

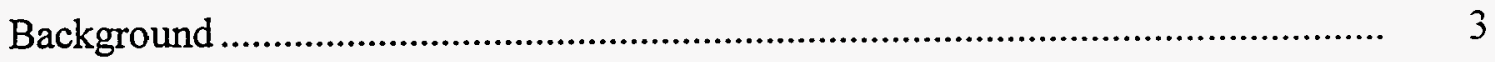

LDDM Theory of Operation .......................................................................

Experiment Equipment Setup ................................................................... 4

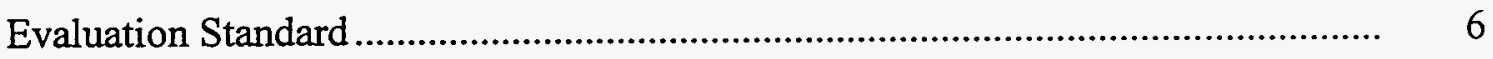

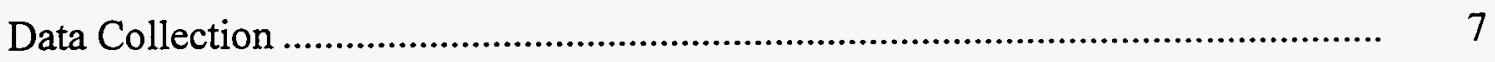

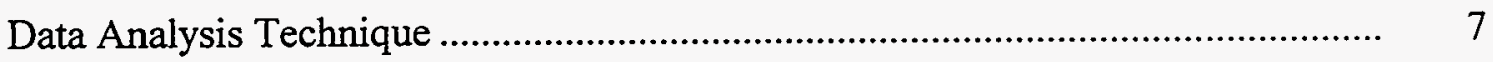

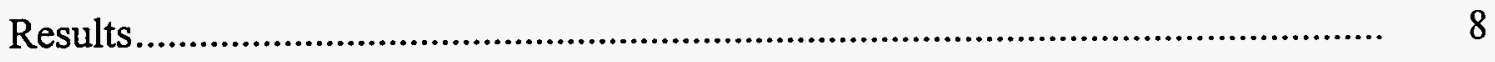

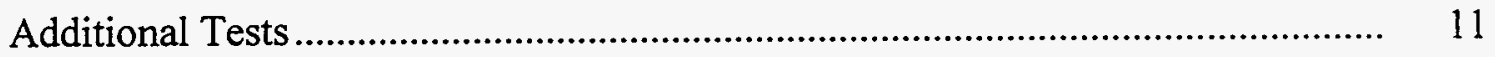

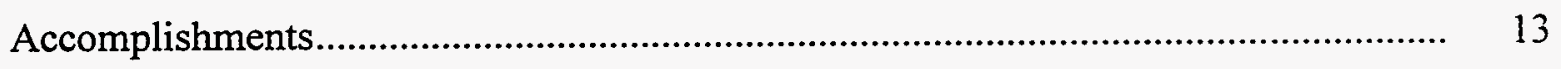

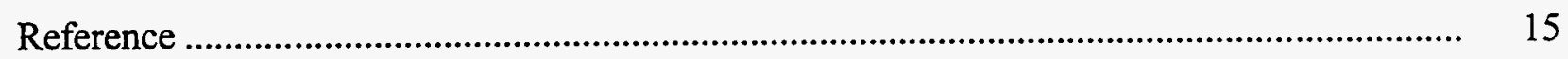

Appendices

A. Data Analysis Software Description .......................................................... 16

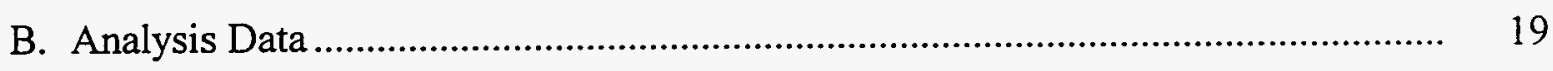




\section{Illustrations}

Figure

Page

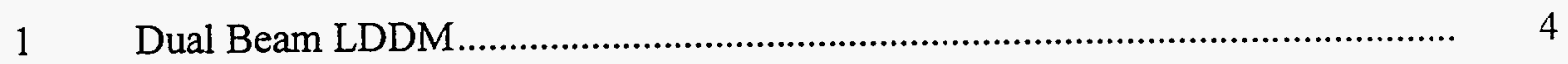

$2 \quad$ Cordax 803 DCC CMM.................................................................... 5

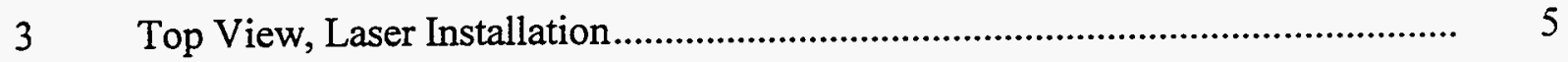

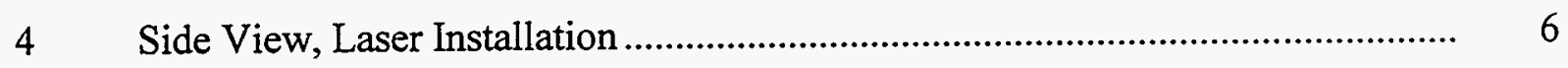

$5 \quad$ Coordinate Standard Sphere Locations..................................................

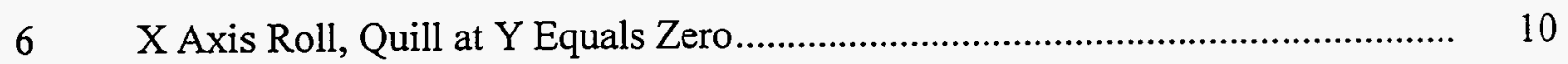

$7 \quad \mathrm{X}$ Axis Roll, Quill at Y Equals Full Travel ............................................ 10

\section{Tables}

Number

Page

$1 \quad$ Maximum Uncertainty of Cordax System ................................................ 8

2 Maximum Uncertainty of LDDM System Without Angular Corrections............. 9

3 Maximum Uncertainty of LDDM System With Angular Corrections................. 9

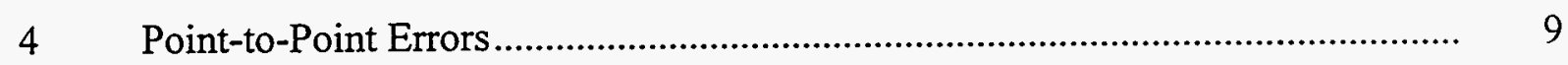

$5 \quad$ Maximum Uncertainty With Point-to-Point and Squareness Corrections ............ 11

$6 \quad$ Average Form Error of Sphere Fits........................................................ 11

$7 \quad$ Fixed Bridge CMM Linear Comparison Data .......................................... 12

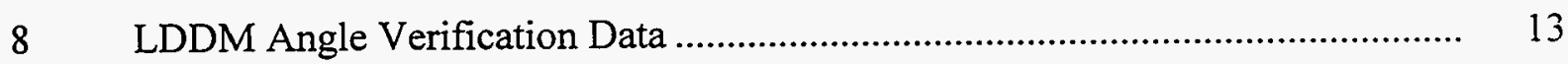




\begin{abstract}
A dual beam laser Doppler displacement measuring system was mounted to a fixed-table, cantilever-type coordinate measuring machine (CMM) to establish the feasibility of real time angular error correction for each CMM axis. The performance improvement was evaluated relative to the CMM's standard scales. The dual beam system proved to have no advantage over a single beam laser due to an inability to measure the actual angular errors at the probe location, but showed potential for substantial accuracy improvement over the standard CMM scales when geometry errors were software corrected.
\end{abstract}

\title{
Summary
}

This project was initiated at the request of Optodyne, Inc. through the Department of Energy's National Machine Tool Partnership Program. The primary purpose was to determine the feasibility of real time angular geometry correction in coordinate measurement using a dual beam laser Doppler displacement measuring (LDDM) system. The experiment was performed on a fixed-table, cantilever-type coordinate measuring machine (CMM) which normally uses linear scales as its displacement measuring system.

The experiment was designed to take data from the CMM's scales and the LDDM system at the same time to provide a fair evaluation of their relative performance. The LDDM was temporarily mounted on the CMM in such a way as to ensure the CMM's restoration to normal service at the conclusion of the project. The laser heads of the LDDM system were mounted to measure linear displacement and yaw angle in the $\mathrm{X}$ axis, linear displacement and pitch angle in the $\mathrm{Y}$ axis, and linear displacement only in the $Z$ axis.

The CMM was controlled and the scale data taken using the normal data collection software running on the system controller. The LDDM system was interfaced to the touch trigger probe via a personal computer, which was performing data collection for the LDDM at the same time as the CMM controller. The evaluation standard used for the project was a three-dimensional coordinate standard (ball plate) certified to an accuracy of $\pm(30$ microinches $+2 \mathrm{ppm})$.

Data collection was performed with the ball plate placed flat on the machine on the machine table and flat approximately 9.5 inches above the machine table. Using the flat positions maximized the ability of the experiment to evaluate $\mathrm{X}$ and $\mathrm{Y}$ axis angular corrections and minimized the influence of a large amount of vibration in the $Z$ axis. Three runs were taken at each position. 
Analysis of the raw linear data showed that the CMM's scale data had a much lower uncertainty than the LDDM data. After correcting for measured angular error, the LDDM's calculated uncertainty was much lower, but still higher than the scale and higher than expected. Also, the form error of the individual measurements for the LDDM data was higher than that of the scale data.

Further analysis and troubleshooting showed that the angular correction did not perform as hoped because the angular error at the location of the LDDM was different than that at the probe location. However, it was shown that using linear and squareness corrections in the software would provide an accuracy improvement of 25 to 38 percent using the LDDM as compared to the CMM's scales. 


\section{Discussion}

\section{Scope and Purpose}

This project was initiated at the request of Optodyne, Inc. under the Department of Energy's (DOE) National Machine Tool Partnership (NMTP) program. The purpose of the NMTP program is for DOE to partner with industry in order to develop machine tool technology. Specifically, this project was initiated to determine the feasibility of real time angular geometry correction in coordinate measurement using a dual beam laser Doppler displacement measuring (LDDM) system.

The selection of the coordinate measuring machine (CMM) used and the design of the experiment were limited by the temporary nature of the project. The CMM had to be available for several months and had to be restored to its original configuration. Therefore, no modifications were made to the CMM's controller or its physical structure.

\section{Activity}

\section{Background}

The AlliedSignal Federal Manufacturing \& Technology Dimensional Metrology group has extensive experience in the application of laser interferometer systems in all areas of dimensional measurement. Optodyne had previously requested technical assistance on the evaluation of an LDDM on a single-axis measuring machine compared to other displacement measuring systems. Additionally, the Dimensional Metrology group has extensive experience in the calibration and evaluation of CMM uncertainties. Because of these factors, Optodyne initiated this project.

\section{LDDM Theory of Operation ${ }^{1}$}

The LDDM is based on the principles of radar, the Doppler effect, and optical heterodyning. Basically, a retroreflector is illuminated by a helium-neon laser beam. The laser beam reflected by the retroreflector is frequency shifted by the motion of the retroreflector, and the phase of the reflected laser beam is proportional to the position of the retroreflector. That is,

$$
X=\frac{c}{2 f}\left(N+\frac{p h i}{2 \pi}\right)
$$

where $X$ is the position of the retroreflector, $c$ is the speed of light, $f$ is the laser frequency, $N$ is the number of $2 \pi$ 's and phi is the phase angle. 
The dual beam system consists of two exit laser beams from each laser head, two return beams, and two retroreflectors. The separation of the two laser beams and retroreflectors is a known distance. By comparing the difference in retroreflector position between the two laser beams, the angle can be calculated. Like laser interferometer systems, the LDDM must be compensated for the refractive index of air in non-standard conditions. The dual beam LDDM is shown in Figure 1.

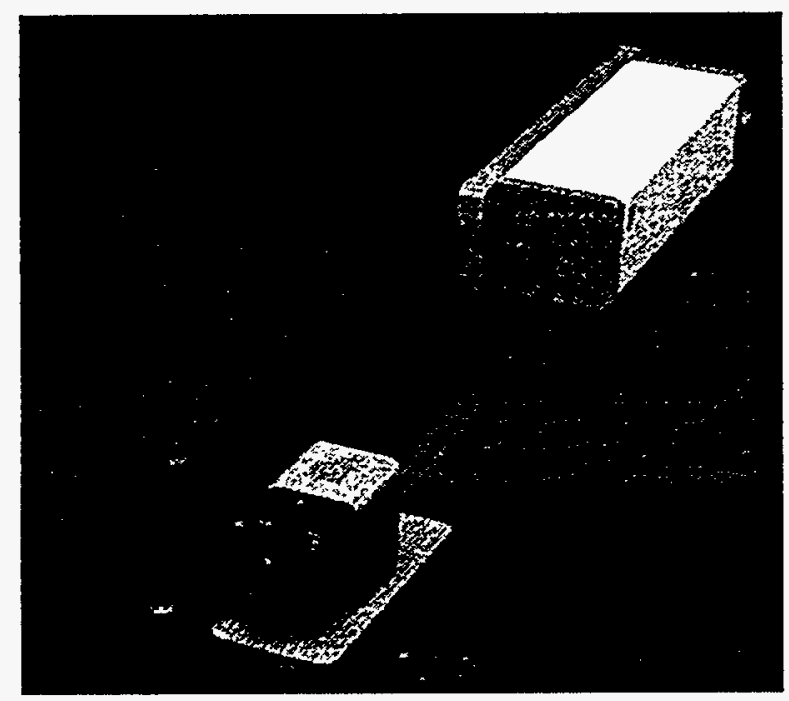

Figure 1. Dual Beam LDDM

\section{Experiment Equipment Setup}

\section{CMM Laser Installation}

The CMM selected for the experiment was a fixed-table, cantilever-type Cordax 803 direct computer-controlled machine. (See Figure 2.) This CMM was selected due to its availability and its design. This type of CMM seemed to be a logical candidate for real time angular correction because of the large Abbe offset in both the $\mathrm{X}$ and $\mathrm{Y}$ axes and because its geometry is not as stable as other CMMs, such as a fixed-bridge type. On a CMM with a more stable geometry, mapping out the errors through the operating software, would likely be a better way to improve the accuracy. 


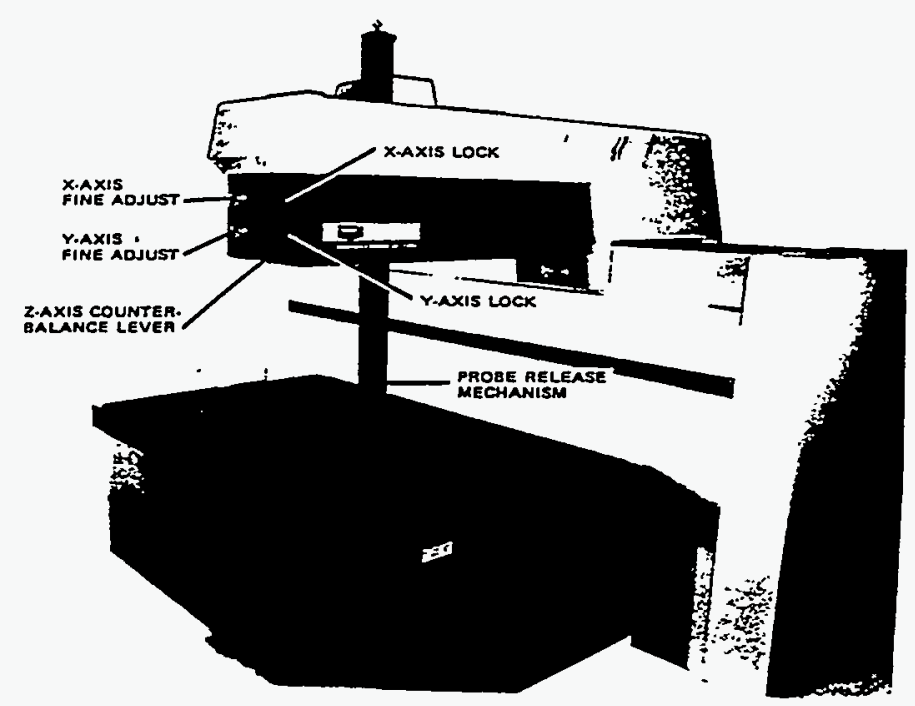

\section{Figure 2. Cordax 803 DCC CMM}

Dual beam laser heads and processors were used for the $X$ and $Y$ axes. Because the $Z$ axis had less likelihood of angular errors and a much smaller Abbe offset, a single beam laser was used. The lasers were installed on the CMM as shown in Figures 3 and 4. On the X axis, the laser head was installed oriented to measure yaw. The yaw orientation was selected due to the large Abbe offset and the probability of angular errors in this direction. The $Y$ axis laser head was oriented to measure pitch. The pitch orientation in this axis was selected due to large Abbe offset and a high probability of angular errors.

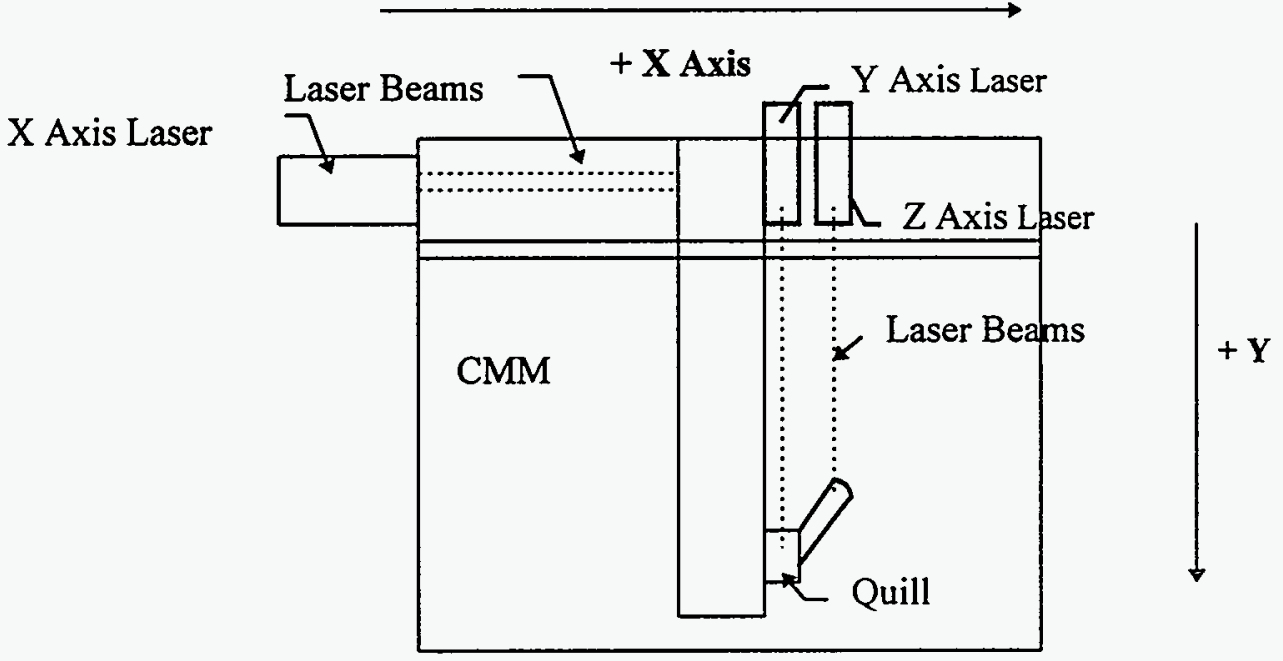

Figure 3. Top View, Laser Installation 


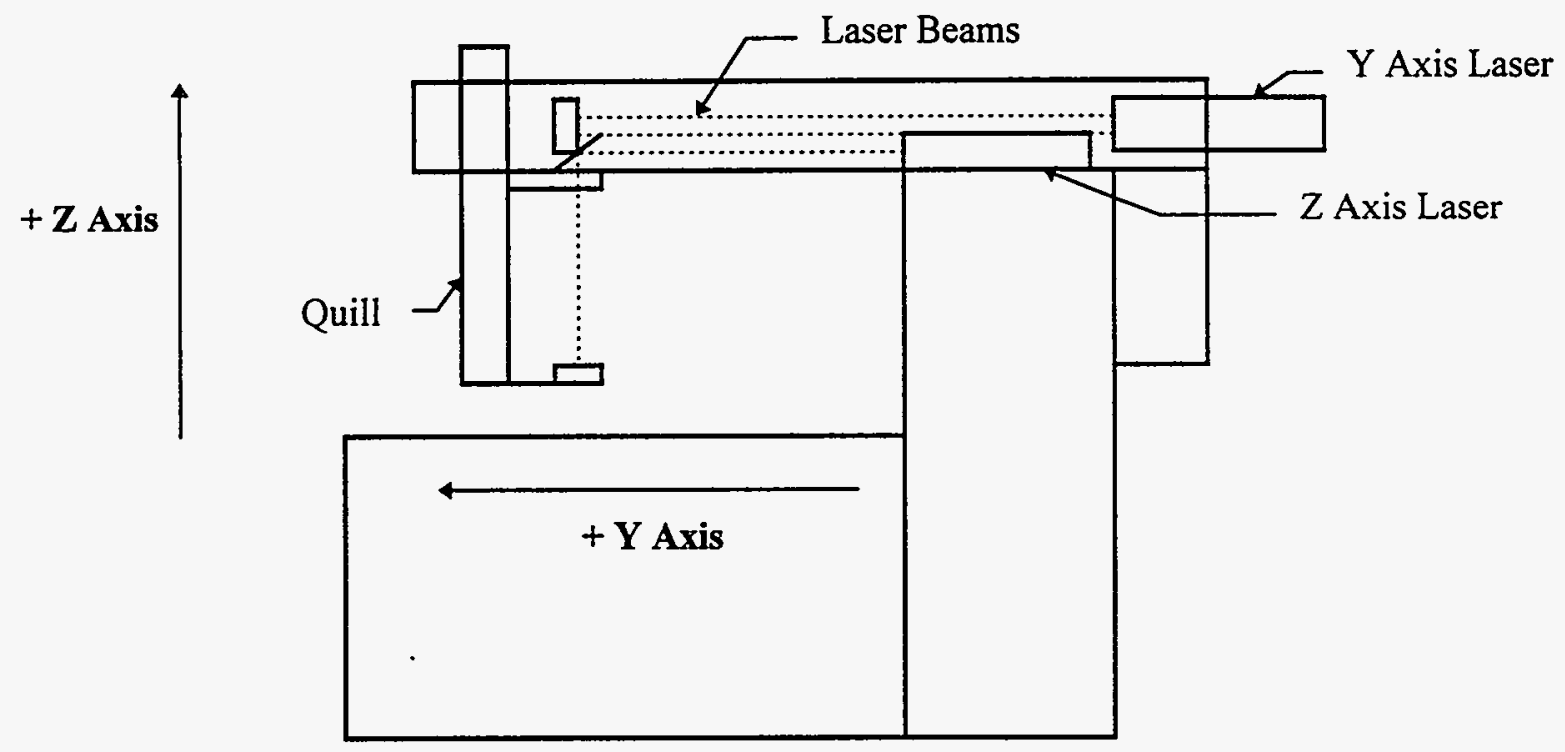

Figure 4. Side View, Laser Installation

\section{CMM Probe and Laser Interface Configuration}

The CMM normally takes measurements using a touch-trigger probe. This probe is basically a normally closed switch that opens with physical contact with the part being measured. The probe is wired as part of a latching circuit in the CMM electronics that latches the current displacement readings from each axis of the $\mathrm{CMM}$ when the probe triggers. It was decided to control the CMM with its normal controller to facilitate the speed and ease of data collection for this project.

The LDDM was configured to have an individual PC interface card for each axis of measurement, that is, one interface card for each linear displacement axis and one for each angular measurement axis, for a total of five cards. Each interface card has a counter and an A-to-D converter. The counter keeps track of the total number of full wavelengths and the A-to-D converter, when initiated, converts the analog phase signal to additional displacement. All five interface cards were wired together to the latching circuit. Therefore, when the touch probe triggered, it latched the displacement readings from the CMM scales and the LDDM system simultaneously.

\section{$\underline{\text { Evaluation Standard }}$}

The standard used to evaluate the performance of the CMM was a three-dimensional coordinate standard (i.e., ball plate). The ball plate is basically an array of tooling spheres arranged in a grid pattern affixed to a steel fixture. The spheres are located nominally in a plane to allow very accurate certification of their relative locations. The sphere-to-sphere distances are certified to an uncertainty of \pm ( 30 microinches $+2 \mathrm{ppm})$. By measuring the ball plate in various orientations, the entire volume of a CMM can be evaluated. The ball plate used for this test had 25 spheres whose locations are depicted in Figure 5. The area used for this evaluation covered approximately 18 by 22 inches and did not use the last row of balls due to limitations of the software written to operate the LDDM. 


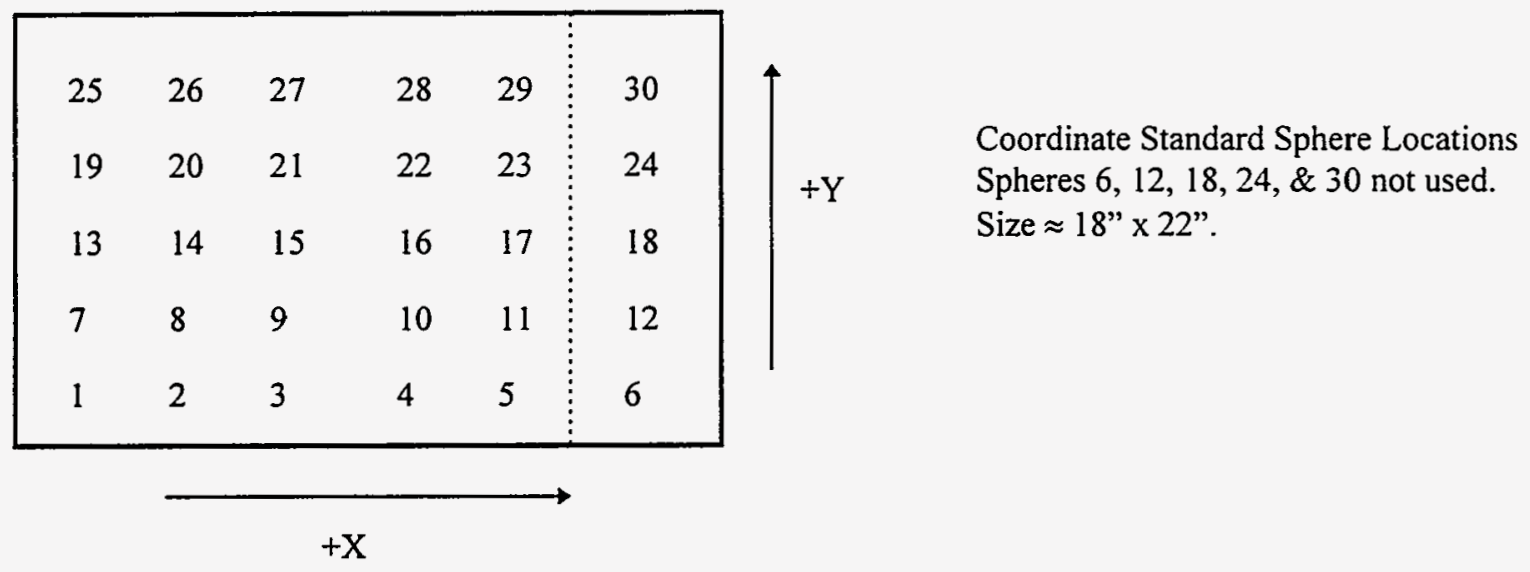

Figure 5. Coordinate Standard Sphere Locations

\section{$\underline{\text { Data Collection }}$}

The data collection scheme was modeled after the method normally used to calibrate and certify the CMM with a couple of modifications. Normally the ball plate is measured in four tilted positions which allow a complete volumetric evaluation of the CMM. Because of the restrictions in modifying the CMM, the Z-axis reflector was mounted in a position that was very prone to vibration. In order to minimize the effect of the $Z$ readings on the evaluation and to maximize the usefulness of the $X$ - and $Y$-axis angular readings, the ball plate positioned flat in the $X-Y$ plane on the machine table. The ball plate was also measured in a second position flat in the $X-Y$ plane at 9.5 inches above the machine table.

The CMM's data collection software for the CMM's scale evaluation was a slightly modified version of the software used for normal calibration data collection. The ball plate's position is manually located by probing two spheres. The software then takes control of the CMM and probes each of the spheres in succession. Nine probings are taken on each sphere and the location of the center of the sphere is calculated, along with the form error of the sphere fit. The calculated sphere center location is then written to a data file. Simultaneously, the nine probings triggered the LDDM interfaces. The values from each of the five axes (three linear and two angular) were written to a data file for later analysis. Three runs were taken at each of the two positions.

\section{Data Analysis Technique}

The data analysis software used was the software normally used for calibration of the CMM. This software uses the data generated during the data collection process and calculates an uncertainty for the CMM. The uncertainty is calculated for axial, planar, and spatial data using the appropriate pairs of spheres for each uncertainty calculation. The software also calculates point-to-point errors in each axis and squareness for each plane. A more detailed explanation of 
the data analysis software output is provided in Appendix A. The Cordax data file was in the correct format to be analyzed directly.

In order to analyze the LDDM data, it first had to be converted from raw axis positions to calculated sphere locations. For the initial analysis, only the linear X, Y, and Z data was used. Each group of nine data points for a given sphere probing was run through a least squares sphere fitting routine, which calculated the location of the sphere's center and the form error of the sphere fit. The data was then analyzed using the data analysis software.

To assess the accuracy of the angular correction of LDDM data, the X-axis and Y-axis linear readings for each probing were first run through the least squares fitting routine. The calculated locations of the sphere centers were then corrected for the angular error readings at that position. The linear correction was calculated by applying the measured angle (at the centerline of the two laser beams) over the distance from the centerline of the laser beams to the sphere location. The corrected sphere locations were then analyzed with the data analysis software.

The data analysis software used has the capability to apply linear corrections to each axis of measurement as well as squareness corrections to each plane of measurement. This option allows determination of the uncertainty of the CMM when it is optimized through either hardware or software.

All of the data sets were re-analyzed using this option and the linear and squareness errors from both positions calculated in the analysis of the raw data to determine their potential 'optimum' performance. For the LDDM, this was done with both the linear data and the angular corrected data.

\section{$\underline{\text { Results }}$}

The complete analysis for each data set is contained in Appendix B. The data shown here highlights the findings of the analysis.

Table 1 shows the maximum calculated uncertainty for the Cordax scale data at each analysis position. The slightly higher uncertainty level with the ball plate positioned on the machine table probably indicates that there was some uncorrected pitch error present in the $Y$ axis.

Table 1. Maximum Uncertainty of Cordax System (Uncertainty is in microinches.)

\begin{tabular}{|c|c|c|c|}
\hline $\begin{array}{c}\text { Measurement } \\
\text { Type }\end{array}$ & $\begin{array}{c}\text { Ball Plate on the } \\
\text { Machine Table }\end{array}$ & $\begin{array}{c}\text { Ball Plate 9.5 Inches } \\
\text { Above the Machine Table }\end{array}$ & Both Positions \\
\hline \hline Axial & 309 & 296 & 300 \\
Planar & 413 & 351 & 382 \\
Spatial & 444 & 366 & 404 \\
\hline
\end{tabular}


Table 2 shows the maximum uncertainty for the linear LDDM data at both positions. This analysis used the linear readings for the $\mathrm{X}$ and $\mathrm{Y}$ axes of the LDDM data without correcting for the angular readings (errors). The much higher uncertainty indicates that large angular errors exist between the centerline of the laser beams and the probe position. The Cordax scale data has already been compensated for these errors so did not show the large uncertainty.

Table 2. Maximum Uncertainty of LDDM System Without Angular Error Correction (Uncertainty is in microinches.)

\begin{tabular}{|c|c|c|c|}
\hline $\begin{array}{c}\text { Measurement } \\
\text { Type }\end{array}$ & $\begin{array}{c}\text { Ball Plate on the } \\
\text { Machine Table }\end{array}$ & $\begin{array}{c}\text { Ball Plate 9.5 Inches } \\
\text { Above the Machine Table }\end{array}$ & Both Positions \\
\hline \hline Axial & 1144 & 1177 & 1157 \\
Planar & 1115 & 1137 & 1125 \\
Spatial & 1240 & 1270 & 1253 \\
\hline
\end{tabular}

Table 3 shows the maximum uncertainties of the LDDM readings after the linear readings had been corrected for the measured angular errors. The uncertainties improved over the uncorrected data, but were still not as good as had been expected. The calculated point-to-point errors shown in Table 4 provided a clue as to what was happening. Using the $\mathrm{Y}$-axis data as an example shows a point-to-point error of $-51.8 \mathrm{ppm}$ in the non-corrected data on the machine table. This would equate to a pitch error in $\mathrm{Y}$ of approximately 10 arcseconds. After angular correction, the $Y$-axis point-to-point error is $+24.5 \mathrm{ppm}$, which would equate to a pitch error of approximately -5 arcseconds. The total spread of measured pitch error was $\approx 15$ arcseconds. The angular error correction over-corrected Y-axis pitch, which implies that the pitch error at the quill is different than that at the laser beams.

Table 3. Maximum Uncertainty of LDDM System With Angular Error Correction (Uncertainty is in microinches.)

\begin{tabular}{|c|c|c|c|}
\hline $\begin{array}{c}\text { Measurement } \\
\text { Type }\end{array}$ & $\begin{array}{c}\text { Ball Plate on the } \\
\text { Machine Table }\end{array}$ & $\begin{array}{c}\text { Ball Plate 9.5 Inches } \\
\text { Above the Machine Table }\end{array}$ & \begin{tabular}{c} 
Both Positions \\
\hline \hline Axial
\end{tabular} \\
\hline \hline Planar & 854 & 379 & 683 \\
Spatial & 679 & 460 & 621 \\
\hline
\end{tabular}

Table 4. Point-to-Point Errors (Parts per million)

\begin{tabular}{|c|c|c|c|c|}
\hline System & Axis & $\begin{array}{c}\text { Ball Plate on } \\
\text { Machine Table }\end{array}$ & $\begin{array}{c}\text { Ball Plate 9.5 Inches } \\
\text { Above Machine Table }\end{array}$ & Both Positions \\
\hline \hline Cordax & $\mathrm{X}$ & -5.0 & -4.3 & -4.6 \\
& $\mathrm{Y}$ & -4.5 & -6.9 & -5.7 \\
\hline LDDM without & $\mathrm{X}$ & -7.6 & -7.5 & -7.5 \\
Angular Correction & $\mathrm{Y}$ & -51.8 & -53.6 & -52.7 \\
\hline LDDM with Angular & $\mathrm{X}$ & -11.6 & -11.8 & -11.7 \\
Correction & $\mathrm{Y}$ & 24.5 & -6.0 & 9.2 \\
\hline
\end{tabular}


Figures 6 and 7 show what happens on the $\mathrm{Y}$ axis as the quill moves from zero to full travel. In Figure 6, the quill is at zero and, for reference purposes, $Y$-pitch error is zero. The $Y$ beam shows a gradual curve upwards. In Figure 7, with the quill at full travel in $Y$, the weight of the quill and saddle have bent the $Y$ beam down and also rolled the whole machine slightly in the $\mathrm{X}$ axis. The net effect is that at the quill, Y-pitch error remains about at zero over the full travel; but at the location of the $Y$-axis laser relative to the saddle, the pitch error is about 12 arcseconds. This was indicated by the $\mathrm{Y}$-axis angular laser readings and verified by using an autocollimator at the location of the $\mathrm{Y}$-axis laser and at the machine table.
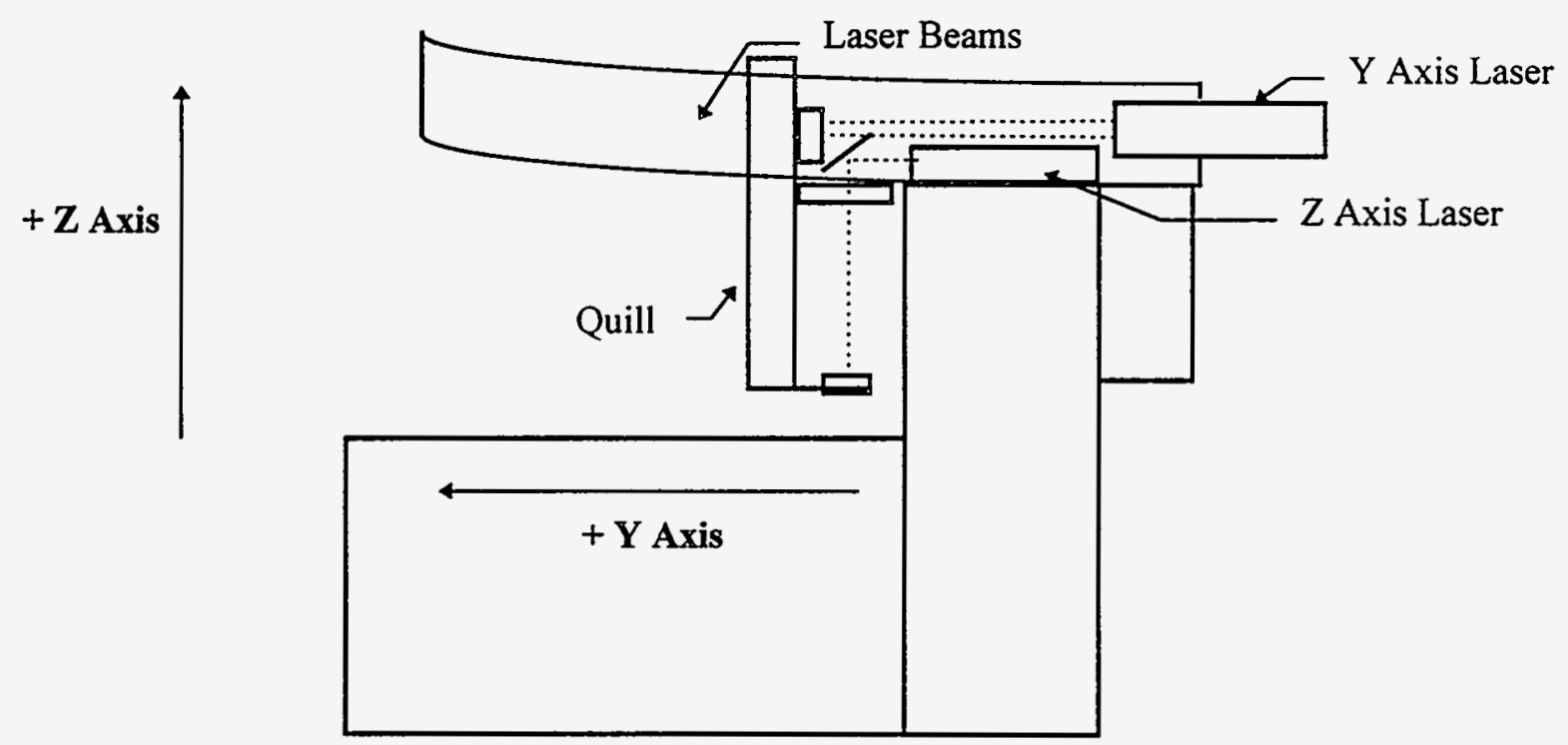

Figure 6. $\mathrm{X}$ Axis Roll, Quill at $\mathrm{Y}$ Equals Zero

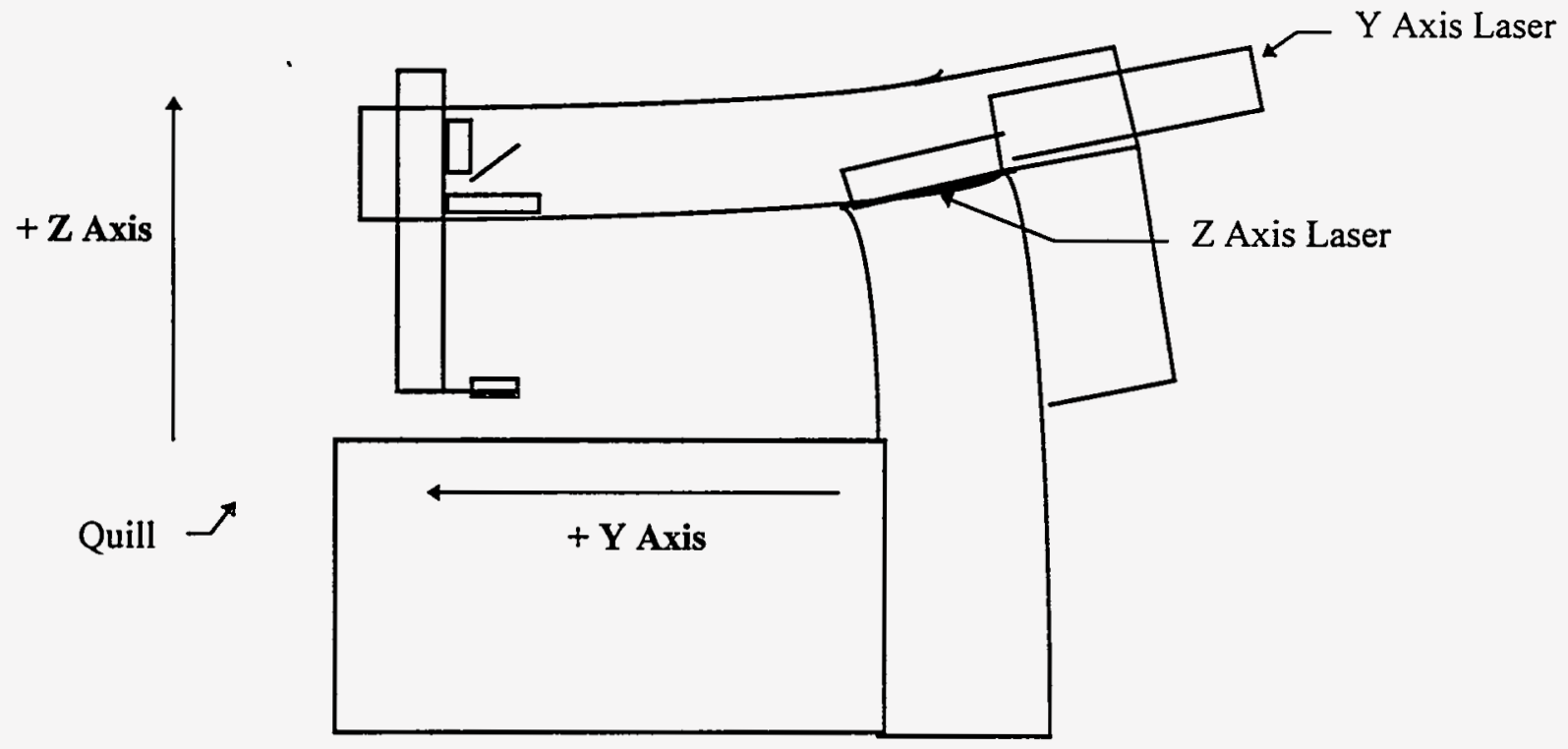

Figure 7. X Axis Roll, Quill at Y Equals Full Travel 
In the final part of the data analysis, point-to-point errors and $X-Y$ squareness errors calculated in the analysis of both positions were corrected in the analysis software to evaluate the potential optimum performance of both the Cordax scales and of the LDDM system. Table 5 shows that the corrected LDDM data shows an uncertainty improvement of 25 to 38 percent over the Cordax scales.

Table 5. Maximum Uncertainty With Point-to-Point and Squareness Corrections (Two positions of data)

\begin{tabular}{|c|c|c|c|}
\hline System & $\begin{array}{c}\text { Axial Uncertainty } \\
\text { (Microinches) }\end{array}$ & $\begin{array}{c}\text { Planar Uncertainty } \\
\text { (Microinches) }\end{array}$ & $\begin{array}{c}\text { Spatial Uncertainty } \\
\text { (Microinches) }\end{array}$ \\
\hline \hline $\begin{array}{c}\text { Cordax } \\
\text { LDDM without Angular }\end{array}$ & 303 & 370 & 370 \\
Correction & 190 & 277 & 282 \\
\hline
\end{tabular}

As a further indication of the CMM's performance, the form error of the sphere fits was evaluated. The touch trigger probe usually contributes the largest portion of this form error. In this test, the difference between the form errors of the Cordax system and the LDDM system also provides an indication of the amount of noise, vibration, and localized scale errors in each system. Table 6 shows the calculated average form error from each system, based on a sample of the sphere fits for each. The form error from the LDDM is significantly higher. This is probably caused by the previously noted vibration and noise in the system. Due to the large number of points taken to fit each sphere, this did not significantly affect the calculated center location.

Table 6. Average Form Error of Sphere Fits

\begin{tabular}{|c|c|}
\hline System & $\begin{array}{c}\text { Form Error } \\
\text { (Microinches) }\end{array}$ \\
\hline \hline Cordax & 187 \\
LDDM & 309 \\
\hline
\end{tabular}

\section{Additional Tests}

After the conclusion of the CMM evaluation, two additional tests were run using the LDDM. For both tests, the LDDM readings were taken from the measurement processor and display instead of the PC interface cards. Compensation for the laser wavelength was not performed during measurement, but corrections were applied in the data analysis.

\section{Fixed Bridge CMM Test}

The first test was an attempt to perform angular error correction on a fixed-bridge CMM, where it was known the geometry was stable enough to eliminate the problems such as that caused by $\mathrm{X}$-axis roll in the previous $\mathrm{CMM}$ evaluation. The CMM used was a granite, air bearing-based machine with a laser interferometer system to measure displacement. The CMM's Y-axis laser interferometer is mounted on the $\mathrm{Y}$-axis carriage approximately 26 inches above the probe location, but in line with the quill. The LDDM laser was placed on the Y-axis carriage, 
approximately 33 inches above the CMM probe location. The LDDM had an offset from the quill of about 3 to 4 inches. The LDDM was set up to measure pitch in the $Y$ axis. A single-axis laser interferometer system was set up in the $\mathrm{Y}$ axis aligned at the probe location, which eliminated any angular errors for its readings.

A single run of data was taken in 2-inch increments over the 36 inches of travel of the CMM's $Y$ axis. The data from the single-axis laser was taken to be the 'true' value since its measurements were not affected by machine geometry. The readings taken from the CMM laser system and the LDDM were compared to the single-axis readings to determine their accuracy. Both sets of readings were proportionally corrected for zero drift during the run. The zero corrected data was then linearly corrected for point-to-point error. The LDDM data was then also corrected for angular error readings. Table 7 shows a summary of the corrected data.

Table 7. Fixed Bridge CMM Linear Comparison Data

\begin{tabular}{|c|c|c|c|c|c|}
\hline $\begin{array}{c}\text { Nominal } \\
\text { Length (Inch) } \\
\end{array}$ & $\begin{array}{c}\text { CMM Laser } \\
\text { Deviations } \\
\text { (Microinch) }\end{array}$ & $\begin{array}{c}\text { LDDM } \\
\text { Deviations } \\
\text { (Microinch) }\end{array}$ & $\begin{array}{c}\text { CMM Laser } \\
\text { Deviations } \\
\text { Corrected } \\
0.17 \text { ppm } \\
\text { (Microinch) } \\
\end{array}$ & $\begin{array}{c}\text { LDDM } \\
\text { Deviations } \\
\text { Corrected } \\
7.54 \text { ppm } \\
\text { (Microinch) } \\
\end{array}$ & $\begin{array}{c}\text { LDDM } \\
\text { Deviations } \\
\text { Corrected 7.54 } \\
\text { ppm \& Angle } \\
\text { (Microinch) } \\
\end{array}$ \\
\hline$\overline{\overline{0}}$ & 0 & 0 & 0 & 0 & 0 \\
\hline 2 & -12 & -18 & -12 & -3 & -63 \\
\hline 4 & 10 & -12 & 9 & 18 & -72 \\
\hline 6 & 12 & -17 & 11 & 29 & 29 \\
\hline 8 & -7 & -53 & -8 & 7 & -53 \\
\hline 10 & -16 & -98 & -18 & -23 & -53 \\
\hline 12 & -15 & -125 & -17 & -35 & -35 \\
\hline 14 & 1 & -135 & -2 & -30 & -60 \\
\hline 16 & 2 & -151 & -1 & -30 & 0 \\
\hline 18 & -6 & -162 & -9 & -26 & -26 \\
\hline 20 & -3 & -176 & -7 & -25 & 5 \\
\hline 22 & 1 & -175 & -3 & -9 & 51 \\
\hline 24 & 13 & -182 & 9 & -1 & 89 \\
\hline 26 & 13 & -172 & 8 & 24 & 144 \\
\hline 28 & 0 & -200 & -5 & 11 & 71 \\
\hline 30 & -1 & -219 & -7 & 7 & 127 \\
\hline 32 & 9 & -231 & 3 & 10 & 70 \\
\hline 34 & 11 & -260 & 5 & -3 & 27 \\
\hline 36 & 17 & -242 & 10 & 30 & 120 \\
\hline 0 & 0 & 0 & 0 & 0 & -30 \\
\hline
\end{tabular}


During the test, vibration or noise in the LDDM system made it difficult to take the individual readings. The readings would vary by about plus or minus 5 microinches. The apparent median reading was the reading recorded. While that noise did not substantially affect the linear data, it may be the cause for bad angular corrections. As the data shows, angular error correction made the LDDM data much worse than the non-corrected data. A contributing factor to this is that the angular errors in this CMM are probably smaller than the noise in the LDDM.

\section{LDDM Angle Accuracy Verification Test}

The second test was simply a verification of the dual beam LDDM's ability to accurately measure angles. This test was performed using a small angle generator which produces angles accurate to one-tenth arcsecond. The results shown in Table 8 indicate that on average the LDDM has reasonably good accuracy in the measurement of angles. However, while taking data, the apparent noise in the system was over an arcsecond and the range of readings over three runs also approached an arcsecond.

Table 8. LDDM Angle Verification Data

\begin{tabular}{|c|c|c|c|c|c|c|}
\hline \multirow{2}{*}{$\begin{array}{c}\text { Nominal } \\
\text { Angle } \\
\text { (Arcseconds) } \\
\end{array}$} & \multicolumn{3}{|c|}{ Calculated Angle (Arcseconds) } & \multirow{2}{*}{$\begin{array}{c}\text { Average } \\
\text { (Arcseconds) }\end{array}$} & \multirow{2}{*}{$\begin{array}{c}\text { Range } \\
\text { (Arcseconds) }\end{array}$} & \multirow{2}{*}{$\begin{array}{c}\text { Average } \\
\text { Deviation } \\
\text { (Arcseconds) }\end{array}$} \\
\hline & Run 1 & Run 2 & Run 3 & & & \\
\hline (0 & 0.00 & 0.00 & 0.00 & 0.00 & 0.00 & 0.00 \\
\hline 5 & 5.06 & 4.88 & 4.69 & 4.88 & 0.38 & -0.12 \\
\hline 10 & 9.56 & 10.13 & 9.94 & 9.88 & 0.56 & -0.12 \\
\hline 20 & 19.69 & 20.44 & 20.25 & 20.13 & 0.75 & 0.13 \\
\hline 30 & 30.00 & 30.19 & 30.00 & 30.06 & 0.19 & 0.06 \\
\hline 60 & 59.63 & 60.00 & 60.00 & 59.75 & 0.38 & -0.25 \\
\hline 120 & 119.45 & 119.82 & 119.63 & 119.63 & 0.38 & -0.37 \\
\hline 300 & 299.27 & 299.27 & 299.08 & 299.21 & 0.19 & -0.79 \\
\hline 600 & 599.29 & 598.54 & 598.73 & 598.85 & 0.75 & -1.15 \\
\hline 0 & -0.19 & 0.19 & -0.19 & -0.06 & 0.38 & -0.06 \\
\hline
\end{tabular}

\section{Accomplishments}

The performance of a coordinate measuring machine (CMM) retrofitted with a dual beam laser Doppler displacement measuring (LDDM) system has been investigated as well as the performance characteristics of the LDDM system.

It has been determined that certain types of CMM architecture are not suited for the application of the LDDM dual beam system. The ability to place the LDDM system in a location which will not undergo angular displacement is critical to the application of real time geometry correction. For this reason the Cordax 803 was found to be unsuitable for the application of a dual beam system. 
Other factors such as vibration, the amount of geometry error present in the CMM, and the accuracy of the CMM will determine the suitability of incorporation of the LDDM system dual beam system. When tested on a CMM with very little angular error, the system showed a loss in performance. The angle accuracy testing did confirm that the LDDM system has the ability to sense angular errors and therefore could be useful on CMMs with angular errors greater than two arcseconds. This is provided the system can be placed in a location on the CMM that is not susceptible to angular displacement. With a reduction in noise, the system could probably be applied on CMMs with much smaller angular errors.

A significant improvement was shown in the performance of the CMM when the LDDM system was used as a displacement measuring system. Using the data from a single beam of the LDDM system showed a potential of 25 to 38 percent improvement over the measurements from the Cordax 803 system. 


\section{Reference}

${ }^{1}$ C. P. Wang, "Using the Laser Doppler Displacement Meter For Precision Positioning and Motion Control," Motion Control, June 1991. 
Appendix A

\section{Data Analysis Software Description}




\section{Data Analysis Software Description}

The data analysis of the measurements is divided into three categories: Axial, Planar, and Spatial measurements. The calibration worksheets list each measurement category on separate pages with the data or measurement type indicated near the top of each page.

Each of the measurement types is further broken down into smaller categories which are common to each. These categories are performance specification, number of measured distances, average absolute deviation, average deviation, standard deviation over the work zone, standard deviation of multiple runs, radial bias of standard, standard deviation of the standard, uncertainty of a single run, uncertainty of three runs, and allowable deviation. The fifteen largest positive and negative deviations are also listed for each measurement type. These smaller categories are further broken down into size groupings which are labeled inch groups.

The two categories listed as performance specifications and allowable deviation are different methods of saying the same thing. Allowable deviation lists the maximum allowable deviation, according to the performance specification, for each size grouping.

The number of measured distances is the total number of average lengths for each size group listed without regard to the number of runs.

The average absolute deviation and the average deviation are self explanatory.

The standard deviation over the work zone is the sample standard deviation of the deviations from nominal of the average lengths. The standard deviation of multiple runs is actually the square root of the average variance within multiple runs.

The radial bias and standard deviation of the standard are the type A and type B standard uncertainties of the ball plate for each size grouping.

The category titled uncertainty of a single run is the uncertainty of a single measurement for the differing size groupings. This is calculated through a root-sum-square (RSS) combination of the average absolute deviation, the standard deviation over the work zone, the standard deviation of multiple runs, the radial bias of the standard, and the standard deviation of the standard. Only two-thirds of the standard deviation of multiple runs is RSSed due to a covariance which exists between the standard deviation over the work zone and the standard deviation of multiple runs. The RSS calculation is multiplied by two for an approximate ninety-five percent confidence interval.

The uncertainty of three runs is the same as the one run uncertainty except that the standard deviation of multiple runs is not RSSed.

The analysis also lists the fifteen largest positive deviations and the fifteen largest negative deviations. For more than one position of data, the largest deviations will be from all positions.

The analysis will also note any deviations beyond the tolerance of the performance specification. 
In addition to the common features, each measurement type includes analysis specific to its type.

The Axial data analysis page will display the average $\mathrm{X}$ and $\mathrm{Y}$ axis point-to-point errors. The analysis program calculates the point-to-point error by first establishing the data type: axial, planar, or spatial. If the data is from an axial measurement, the measurement axis is determined. For each axis, the deviation from nominal for the axial measurements is averaged. The data is collected from a ball plate which is placed approximately parallel to the XY plane in two positions. The first resting at the table surface and the second raised 9.5 inches above the table surface. The point-to-point errors from both positions were used when corrections were applied to the data.

The Planar data analysis page will show the calculated XY squareness in parts per million and in arcseconds. The squareness was calculated by analyzing the distance between six sphere pairs. A line between each sphere pair forms a diagonal in the XY plane. Half of the sphere pairs form a line at approximately 45 degrees to the positive $\mathrm{X}$ axis while the other half form a line at approximately 135 degrees from the positive $\mathrm{X}$ axis. The squareness error from both positions was used when corrections were applied to the data.

The Spatial data analysis page divides the data into additional groups of nominal lengths compared to the Planar analysis page. Because only flat positions were tested in this project, there is not a significant difference between the Planar and Spatial analysis pages. 
Appendix B

Analysis Data 
Cordax data taken with ball plate on machine table. No corrections applied.

\begin{tabular}{llll}
\hline \multicolumn{5}{c}{16000 Ball plate } & Exp. date: $08-25-96$ \\
Software: $\quad$ Name PC1808, & ID\# CS-09P-144, Issue A, Revision 06/02/95 \\
\hline Inspected by XXX & Department XXX Inspection Date: $01-25-1996$ \\
\hline
\end{tabular}
The distances are in inches and deviations in microinches.

Axial Data $\quad$ Performance Specification $=+/-(0.00035$ inch $+17 \mathrm{ppm})$

\begin{tabular}{lrrrr}
\multicolumn{1}{c}{ Inch Groups } & \multicolumn{1}{c}{$\frac{5}{20}$} & & $5-12$ & \\
Number measured distances & 97 & 99 & 30 \\
Average absolute deviation & -11 & -44 & -81 \\
Average deviation & 117 & 111 & 64 \\
Std dev over work zone & 28 & 26 & 39 \\
Std dev of multiple runs & 6 & 7 & 8 \\
Radial bias of standard & 17 & 21 & 25 \\
Std dev of the standard & 309 & 304 & 228 \\
Uncertainty of single run & 306 & 301 & 219 \\
Uncertainty of three runs & 427 & 503 & 580 \\
Allowable deviation & & &
\end{tabular}

These data are the 15 most positive and 15 most negative deviations with their ball plate position, sphere pair and nominal distance; respectively ranked as a percentage of the Axial allowable deviation.

\begin{tabular}{|c|c|c|c|c|c|c|c|c|c|}
\hline Position & \multicolumn{2}{|c|}{ Spheres } & Distance & Deviation & Position & \multicolumn{2}{|c|}{ Spheres } & Distance & Deviation \\
\hline 1 & 4 & 16 & 9.000 & 202 & 1 & 13 & 19 & 4.500 & -218 \\
\hline 1 & 5 & 17 & 9.000 & 194 & 1 & 13 & 25 & 9.000 & -241 \\
\hline 1 & 4 & 10 & 4.500 & 144 & 1 & 16 & 28 & 9.000 & -231 \\
\hline 1 & 3 & 9 & 4.500 & 140 & 1 & 17 & 29 & 9.000 & -230 \\
\hline 1 & 1 & 13 & 9.000 & 165 & 1 & 15 & 27 & 9.000 & -204 \\
\hline 1 & 5 & 11 & 4.500 & 138 & 1 & 16 & 22 & 4.500 & -169 \\
\hline 1 & 3 & 15 & 9.000 & 161 & 1 & 15 & 21 & 4.500 & -167 \\
\hline 1 & 2 & 8 & 4.500 & 130 & 1 & 17 & 23 & 4.500 & -166 \\
\hline 1 & 2 & 14 & 9.000 & 141 & 1 & 14 & 26 & 9.000 & -177 \\
\hline 1 & 1 & 7 & 4.501 & 110 & 1 & 14 & 20 & 4.500 & -145 \\
\hline 1 & 9 & 10 & 5.601 & 90 & 1 & 7 & 19 & 9.000 & -163 \\
\hline 1 & 21 & 22 & 5.600 & 83 & 1 & 7 & 25 & 13.500 & -187 \\
\hline 1 & 27 & 28 & 5.600 & 80 & 1 & 25 & 27 & 11.200 & -173 \\
\hline 1 & 3 & 4 & 5.600 & 69 & 1 & 9 & 27 & 13.500 & -183 \\
\hline 1 & 15 & 16 & 5.600 & 62 & 1 & 11 & 29 & 13.500 & -174 \\
\hline
\end{tabular}

0 of 100 Single-axis measurements exceed the Axial Allowable Deviation. The following data are an estimate of the CMM axial point-to-point errors:

$\mathrm{X}$ axis: average point-to-point error is $-5.0 \mathrm{ppm}$.

$\mathrm{Y}$ axis: average point-to-point error is $-4.5 \mathrm{ppm}$. 


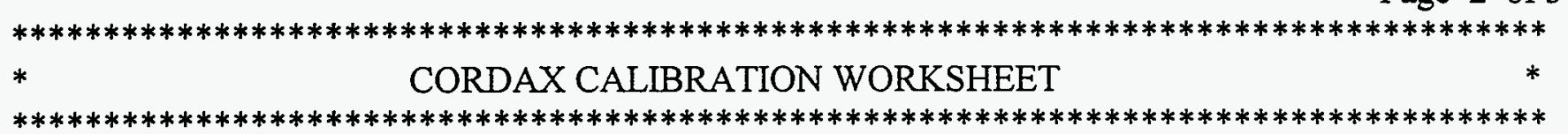

Cordax data taken with ball plate on machine table. No corrections applied.

Inspected by XXX Department XXX Inspection Date: 01-25-1996

The distances are in inches and deviations in microinches.

Planar Data Performance Specification $=+/-(0.00035$ inch $+25 \mathrm{ppm})$

Inch Groups

Number measured distances

Average absolute deviation

Average deviation

Std dev over work zone

Std dev of multiple runs

Radial bias of standard

Std dev of the standard

Uncertainty of single run

Uncertainty of three runs

Allowable deviation

$\begin{array}{rrrrrr}\frac{\leq 5}{20} & \frac{5-6}{20} & \frac{6-10}{47} & \frac{10-12}{39} & \frac{12-17}{78} & \frac{>17}{96} \\ 97 & 73 & 129 & 124 & 119 & 123 \\ -11 & -35 & -42 & -58 & -68 & -92 \\ 117 & 68 & 154 & 161 & 140 & 130 \\ 28 & 18 & 31 & 31 & 39 & 43 \\ 6 & 6 & 7 & 7 & 8 & 9 \\ 17 & 18 & 21 & 23 & 25 & 29 \\ 309 & 206 & 408 & 413 & 376 & 369 \\ 306 & 204 & 405 & 410 & 371 & 362 \\ 463 & 490 & 575 & 630 & 688 & 800\end{array}$

These data are the 15 most positive and 15 most negative deviations with their ball plate position, sphere pair and nominal distance; respectively ranked as a percentage of the Planar allowable deviation.

\begin{tabular}{|c|c|c|c|c|c|c|c|c|c|}
\hline Position & \multicolumn{2}{|c|}{ Spheres } & Distance & Deviation & Position & \multicolumn{2}{|c|}{ Spheres } & Distance & Deviation \\
\hline 1 & 3 & 10 & 7.184 & 273 & 1 & 13 & 20 & 7.184 & -434 \\
\hline 1 & 3 & 16 & 10.600 & 296 & 1 & 7 & 20 & 10.600 & -416 \\
\hline 1 & 4 & 16 & 9.000 & 202 & 1 & 13 & 21 & 12.070 & -439 \\
\hline 1 & 21 & 28 & 7.184 & 186 & 1 & 7 & 21 & 14.368 & -476 \\
\hline 1 & 2 & 13 & 10.600 & 211 & 1 & 13 & 26 & 10.600 & -406 \\
\hline 1 & 5 & 17 & 9.000 & 194 & 1 & 16 & 23 & 7.184 & -346 \\
\hline 1 & 2 & 16 & 14.368 & 222 & 1 & 13 & 27 & 14.368 & -408 \\
\hline 1 & 4 & 10 & 4.500 & 144 & 1 & 16 & 29 & 10.600 & -347 \\
\hline 1 & 5 & 16 & 10.600 & 190 & 1 & 14 & 21 & 7.184 & -294 \\
\hline 1 & 3 & 9 & 4.500 & 140 & 1 & 10 & 23 & 10.599 & -330 \\
\hline 1 & 5 & 11 & 4.500 & 138 & 1 & 7 & 27 & 17.541 & -418 \\
\hline 1 & 2 & 10 & 12.071 & 193 & 1 & 7 & 26 & 14.615 & -376 \\
\hline 1 & 1 & 13 & 9.000 & 165 & 1 & 13 & 19 & 4.500 & -218 \\
\hline 1 & 2 & 8 & 4.500 & 130 & 1 & 7 & 23 & 24.140 & -432 \\
\hline 1 & 3 & 15 & 9.000 & 161 & 1 & 10 & 29 & 14.615 & -323 \\
\hline
\end{tabular}

0 of 3001 and 2 Axis Measurements exceed the Planar Allowable Deviation. The following data are an estimate of the CMM planar squareness errors: The indicated $\mathrm{XY}$ plane squareness is 8.7 (1.80 arcseconds).

* May be affected by yaw, pitch, roll, and straightness of the included axes. 
Cordax data taken with ball plate on machine table. No corrections applied.

Inspected by XXX Department XXX Inspection Date: 01-25-1996

The distances are in inches and deviations in microinches.

Spatial Data Performance Specification $=+/-(0.00035$ inch $+30 \mathrm{ppm})$

Inch Groups

Number measured distances

Average absolute deviation

Average deviation

Std dev over work zone

Std dev of multiple runs

Radial bias of standard

Std dev of the standard

Uncertainty of single run

Uncertainty of three runs

Allowable deviation

$\begin{array}{rrrrrrrr}\leq 6 & \frac{6-10}{40} & \frac{10-12}{47} & \underline{1214} & \underline{14-17} & \underline{1719} & \underline{1924} & \frac{24}{44} \\ 85 & 129 & 124 & 110 & 125 & 105 & 130 & 152 \\ 23 & -42 & -58 & -56 & -77 & -67 & -102 & -135 \\ 95 & 154 & 161 & 133 & 146 & 120 & 127 & 153 \\ 23 & 31 & 31 & 36 & 41 & 42 & 43 & 49 \\ 6 & 6 & 7 & 7 & 8 & 8 & 9 & 10 \\ 17 & 19 & 22 & 23 & 25 & 28 & 30 & 34 \\ 261 & 408 & 413 & 354 & 394 & 331 & 375 & 444 \\ 258 & 405 & 410 & 349 & 388 & 324 & 368 & 437 \\ 485 & 566 & 668 & 712 & 782 & 872 & 922 & 1074\end{array}$

These data are the 15 most positive and 15 most negative deviations with their ball plate position, sphere pair and nominal distance; respectively ranked as a percentage of the Spatial allowable deviation.

\begin{tabular}{|c|c|c|c|c|c|c|c|c|c|}
\hline Position & \multicolumn{2}{|c|}{ Spheres } & Distance & Deviation & Position & $\underline{\mathrm{Sph}}$ & & Distance & Deviation \\
\hline 1 & 3 & 10 & 7.184 & 273 & 1 & 13 & 20 & 7.184 & -434 \\
\hline 1 & 3 & 16 & 10.600 & 296 & 1 & 7 & 20 & 10.600 & -416 \\
\hline 1 & 21 & 28 & 7.184 & 186 & 1 & 13 & 21 & 12.070 & -439 \\
\hline 1 & 4 & 16 & 9.000 & 202 & 1 & 16 & 23 & 7.184 & -346 \\
\hline 1 & 2 & 13 & 10.600 & 211 & 1 & 7 & 21 & 14.368 & -476 \\
\hline 1 & 5 & 17 & 9.000 & 194 & 1 & 13 & 26 & 10.600 & -406 \\
\hline 1 & 4 & 10 & 4.500 & 144 & 1 & 13 & 27 & 14.368 & -408 \\
\hline 1 & 3 & 9 & 4.500 & 140 & 1 & 16 & 29 & 10.600 & -347 \\
\hline 1 & 5 & 11 & 4.500 & 138 & 1 & 14 & 21 & 7.184 & -294 \\
\hline 1 & 5 & 16 & 10.600 & 190 & 1 & 10 & 23 & 10.599 & -330 \\
\hline 1 & 2 & 16 & 14.368 & 222 & 1 & 7 & 26 & 14.615 & -376 \\
\hline 1 & 2 & 10 & 12.071 & 193 & 1 & 7 & 27 & 17.541 & -418 \\
\hline 1 & 2 & 8 & 4.500 & 130 & 1 & 13 & 19 & 4.500 & -218 \\
\hline 1 & 1 & 13 & 9.000 & 165 & 1 & 10 & 29 & 14.615 & -323 \\
\hline 1 & 3 & 15 & 9.000 & 161 & 1 & 7 & 23 & 24.140 & -432 \\
\hline
\end{tabular}

0 of 300 Total Radial Measurements exceed the Spatial Allowable Deviation. 
Cordax data taken with ball plate raised 9.5 inches above machine table. No corrections applied.

$$
16000 \text { Ball plate Exp. date: 08-25-96 }
$$

Software: Name PC1808, ID\# CS-09P-144, Issue A, Revision 06/02/95

Inspected by XXX $\quad$ Department XXX $\quad$ Inspection Date: 01-25-1996

The distances are in inches and deviations in microinches.

Axial Data Performance Specification $=+/-(0.00035$ inch $+17 \mathrm{ppm})$

\begin{tabular}{lrrr}
\multicolumn{1}{c}{ Inch Groups } & $\leq 5$ & $\mathbf{5 - 1 2}$ & $\geq 12$ \\
Number measured distances & 20 & 50 & 30 \\
Average absolute deviation & 87 & 95 & 94 \\
Average deviation & -17 & -50 & -94 \\
Std dev over work zone & 117 & 102 & 53 \\
Std dev of multiple runs & 17 & 18 & 23 \\
Radial bias of standard & 6 & 7 & 8 \\
Std dev of the standard & 17 & 21 & 25 \\
Uncertainty of single run & 296 & 283 & 225 \\
Uncertainty of three runs & 295 & 282 & 222 \\
Allowable deviation & 427 & 503 & 580
\end{tabular}

These data are the 15 most positive and 15 most negative deviations with their ball plate position, sphere pair and nominal distance; respectively ranked as a percentage of the Axial allowable deviation.

\begin{tabular}{|c|c|c|c|c|c|c|c|c|c|}
\hline Position & \multicolumn{2}{|c|}{ Spheres } & Distance & Deviation & Position & \multicolumn{2}{|c|}{ Spheres } & Distance & Deviation \\
\hline 1 & 3 & 9 & 4.500 & 129 & 1 & 13 & 19 & 4.500 & -217 \\
\hline 1 & 5 & 11 & 4.500 & 124 & 1 & 15 & 21 & 4.500 & -206 \\
\hline 1 & 4 & 10 & 4.500 & 116 & 1 & 14 & 20 & 4.500 & -206 \\
\hline 1 & 2 & 8 & 4.500 & 107 & 1 & 9 & 21 & 9.000 & -223 \\
\hline 1 & 1 & 7 & 4.501 & 100 & 1 & 8 & 20 & 9.000 & -214 \\
\hline 1 & 1 & 13 & 9.000 & 115 & 1 & 16 & 22 & 4.500 & -180 \\
\hline 1 & 5 & 17 & 9.000 & 114 & 1 & 17 & 23 & 4.500 & -179 \\
\hline 1 & 3 & 15 & 9.000 & 113 & 1 & 7 & 19 & 9.000 & -202 \\
\hline 1 & 4 & 16 & 9.000 & 105 & 1 & 10 & 22 & 9.000 & -191 \\
\hline 1 & 21 & 22 & 5.600 & 89 & 1 & 16 & 28 & 9.000 & -188 \\
\hline 1 & 2 & 14 & 9.000 & 99 & 1 & 11 & 23 & 9.000 & -188 \\
\hline 1 & 9 & 10 & 5.601 & 86 & 1 & 14 & 26 & 9.000 & -188 \\
\hline 1 & 15 & 16 & 5.600 & 81 & 1 & 13 & 25 & 9.000 & -176 \\
\hline 1 & 27 & 28 & 5.600 & 70 & 1 & 10 & 28 & 13.500 & -199 \\
\hline 1 & 3 & 4 & 5.600 & 55 & 1 & 8 & 26 & 13.500 & -196 \\
\hline
\end{tabular}

0 of 100 Single-axis measurements exceed the Axial Allowable Deviation.

The following data are an estimate of the CMM axial point-to-point errors:

$\mathrm{X}$ axis: average point-to-point error is $-4.3 \mathrm{ppm}$.

$\mathrm{Y}$ axis: average point-to-point error is $-6.9 \mathrm{ppm}$. 
Cordax data taken with ball plate raised 9.5 inches above machine table. No corrections applied.

Inspected by XXX Department XXX Inspection Date: 01-25-1996

The distances are in inches and deviations in microinches.

Planar Data $\quad$ Performance Specification $=+/-(0.00035$ inch $+25 \mathrm{ppm})$

\begin{tabular}{lrrrrrr}
\multicolumn{1}{c}{ Inch Groups } & $\frac{\leq 5}{20}$ & $\frac{5-6}{20}$ & $\frac{6-10}{47}$ & $\frac{10-12}{39}$ & $\frac{12-17}{78}$ & $\frac{17}{96}$ \\
Number measured distances & 87 & 70 & 113 & 112 & 111 & 111 \\
Average absolute deviation & -17 & -32 & -53 & -71 & -82 & -100 \\
Average deviation & 117 & 68 & 132 & 132 & 116 & 97 \\
Std dev over work zone & 17 & 17 & 19 & 20 & 22 & 22 \\
Std dev of multiple runs & 6 & 6 & 7 & 7 & 8 & 9 \\
Radial bias of standard & 17 & 18 & 21 & 23 & 25 & 29 \\
Std dev of the standard & 296 & 201 & 351 & 351 & 327 & 304 \\
Uncertainty of single run & 295 & 199 & 350 & 349 & 325 & 301 \\
Uncertainty of three runs & 463 & 490 & 575 & 630 & 688 & 800 \\
Allowable deviation & & & & & &
\end{tabular}

These data are the 15 most positive and 15 most negative deviations with their ball plate position, sphere pair and nominal distance; respectively ranked as a percentage of the Planar allowable deviation.

\begin{tabular}{|c|c|c|c|c|c|c|c|c|c|}
\hline Position & \multicolumn{2}{|c|}{ Spheres } & Distance & Deviation & Position & \multicolumn{2}{|c|}{ Spheres } & Distance & Deviation \\
\hline 1 & 3 & 10 & 7.184 & 260 & 1 & 13 & 20 & 7.184 & -357 \\
\hline 1 & 2 & 10 & 12.071 & 210 & 1 & 7 & 20 & 10.600 & -382 \\
\hline 1 & 3 & 16 & 10.600 & 198 & 1 & 7 & 21 & 14.368 & -415 \\
\hline 1 & 3 & 9 & 4.500 & 129 & 1 & 10 & 23 & 10.599 & -339 \\
\hline 1 & 21 & 28 & 7.184 & 145 & 1 & 16 & 23 & 7.184 & -288 \\
\hline 1 & 5 & 11 & 4.500 & 124 & 1 & 13 & 21 & 12.070 & -353 \\
\hline 1 & 2 & 9 & 7.184 & 136 & 1 & 14 & 21 & 7.184 & -278 \\
\hline 1 & 4 & 10 & 4.500 & 116 & 1 & 13 & 26 & 10.600 & -318 \\
\hline 1 & 2 & 8 & 4.500 & 107 & 1 & 8 & 21 & 10.600 & -292 \\
\hline 1 & 3 & 11 & 12.070 & 148 & 1 & 13 & 19 & 4.500 & -217 \\
\hline 1 & 2 & 16 & 14.368 & 160 & 1 & 7 & 26 & 14.615 & -322 \\
\hline 1 & 1 & 7 & 4.501 & 100 & 1 & 15 & 21 & 4.500 & -206 \\
\hline 1 & 1 & 13 & 9.000 & 115 & 1 & 14 & 20 & 4.500 & -206 \\
\hline 1 & 5 & 17 & 9.000 & 114 & 1 & 13 & 27 & 14.368 & -315 \\
\hline 1 & 3 & 15 & 9.000 & 113 & 1 & 7 & 27 & 17.541 & -341 \\
\hline
\end{tabular}

0 of 3001 and 2 Axis Measurements exceed the Planar Allowable Deviation. The following data are an estimate of the CMM planar squareness errors:

The indicated $\mathrm{XY}$ plane squareness is 5.4 (1.11 arcseconds).

* May be affected by yaw, pitch, roll, and straightness of the included axes. 
Cordax data taken with ball plate 9.5 inches above machine table. No corrections applied.

Inspected by XXX Department XXX Inspection Date: 01-25-1996

The distances are in inches and deviations in microinches.

Spatial Data Performance Specification $=+/-(0.00035$ inch $+30 \mathrm{ppm})$

\begin{tabular}{|c|c|c|c|c|c|c|c|c|}
\hline Inch Groups & $\leq 6$ & $\underline{6-10}$ & $\underline{10-12}$ & $\underline{1214}$ & $\underline{14-17}$ & 1719 & $\underline{1924}$ & $\geq 24$ \\
\hline Number measured distances & 40 & 47 & 39 & 34 & 44 & $\overline{41}$ & 39 & \\
\hline Average absolute deviation & 79 & 113 & 112 & 110 & 111 & 95 & 115 & \\
\hline Average deviation & -24 & -53 & -71 & -63 & -96 & -79 & -105 & \\
\hline Std dev over work zone & 95 & 132 & 132 & 118 & 114 & 92 & 95 & \\
\hline ttd dev of multiple runs & 17 & 19 & 20 & 23 & 21 & 21 & 22 & \\
\hline adial bias of standard & 6 & 6 & 7 & 7 & 8 & 8 & 9 & \\
\hline d dev of the standard & 17 & 19 & 22 & 23 & 25 & 28 & 30 & \\
\hline ncertainty of single run & 251 & 351 & 351 & 328 & 325 & 273 & 306 & \\
\hline acertainty of three runs & 249 & 349 & 349 & 326 & 323 & 271 & 304 & \\
\hline Jlowable deviation & 485 & 566 & 668 & 712 & 782 & 872 & 922 & \\
\hline
\end{tabular}

These data are the 15 most positive and 15 most negative deviations with their ball plate position, sphere pair and nominal distance; respectively ranked as a percentage of the Spatial allowable deviation.

\begin{tabular}{|c|c|c|c|c|c|c|c|c|c|}
\hline Position & \multicolumn{2}{|c|}{ Spheres } & Distance & Deviation & Position & \multicolumn{2}{|c|}{ Spheres } & Distance & Deviation \\
\hline 1 & 3 & 10 & 7.184 & 260 & 1 & 13 & 20 & 7.184 & -357 \\
\hline 1 & 3 & 16 & 10.600 & 198 & 1 & 7 & 20 & 10.600 & -382 \\
\hline 1 & 2 & 10 & 12.071 & 210 & 1 & 7 & 21 & 14.368 & -415 \\
\hline 1 & 3 & 9 & 4.500 & 129 & 1 & 16 & 23 & 7.184 & -288 \\
\hline 1 & 21 & 28 & 7.184 & 145 & 1 & 10 & 23 & 10.599 & -339 \\
\hline 1 & 5 & 11 & 4.500 & 124 & 1 & 13 & 21 & 12.070 & -353 \\
\hline 1 & 2 & 9 & 7.184 & 136 & 1 & 14 & 21 & 7.184 & -278 \\
\hline 1 & 4 & 10 & 4.500 & 116 & 1 & 13 & 26 & 10.600 & -318 \\
\hline 1 & 2 & 8 & 4.500 & 107 & 1 & 13 & 19 & 4.500 & -217 \\
\hline 1 & 3 & 11 & 12.070 & 148 & 1 & 8 & 21 & 10.600 & -292 \\
\hline 1 & 1 & 7 & 4.501 & 100 & 1 & 15 & 21 & 4.500 & -206 \\
\hline 1 & 2 & 16 & 14.368 & 160 & 1 & 14 & 20 & 4.500 & -206 \\
\hline 1 & 1 & 13 & 9.000 & 115 & 1 & 7 & 26 & 14.615 & -322 \\
\hline 1 & 5 & 17 & 9.000 & 114 & 1 & 13 & 27 & 14.368 & -315 \\
\hline 1 & 3 & 15 & 9.000 & 113 & 1 & 7 & 27 & 17.541 & -341 \\
\hline
\end{tabular}

0 of 300 Total Radial Measurements exceed the Spatial Allowable Deviation. 
Cordax data taken with both positions analyzed. No corrections applied.

\begin{tabular}{llll}
\hline \multicolumn{5}{c}{16000 Ball plate Exp. date: $08-25-96$} \\
Software: & Name PC1808, & ID\# CS-09P-144, $\quad$ Issue A, $\quad$ Revision 06/02/95 \\
\hline Inspected by XXX Department XXX Inspection Date: $01-25-1996$ \\
\hline
\end{tabular}
The distances are in inches and deviations in microinches.

Axial Data Performance Specification $=+/-(0.00035$ inch $+17 \mathrm{ppm})$

\begin{tabular}{|c|c|c|c|}
\hline Inch Groups & $\leq 5$ & $\underline{5-12}$ & $\geq 12$ \\
\hline Number measured distances & 40 & 100 & 60 \\
\hline Average absolute deviation & 92 & 97 & 89 \\
\hline Average deviation & -14 & -47 & -87 \\
\hline Std dev over work zone & 116 & 106 & 59 \\
\hline Std dev of multiple runs & 23 & 23 & 32 \\
\hline Radial bias of standard & 6 & 7 & \\
\hline Std dev of the standard & 17 & 21 & 25 \\
\hline Uncertainty of single run & 300 & 293 & 226 \\
\hline Uncertainty of three runs & 298 & 291 & 220 \\
\hline Allowable deviation & 427 & 503 & 58 \\
\hline
\end{tabular}

These data are the 15 most positive and 15 most negative deviations with their ball plate position, sphere pair and nominal distance; respectively ranked as a percentage of the Axial allowable deviation.

\begin{tabular}{|c|c|c|c|c|c|c|c|c|c|}
\hline Position & \multicolumn{2}{|c|}{ Spheres } & Distance & Deviation & Position & \multicolumn{2}{|c|}{ Spheres } & Distance & Deviation \\
\hline 2 & 4 & 16 & 9.000 & 202 & 2 & 13 & 19 & 4.500 & -218 \\
\hline 2 & 5 & 17 & 9.000 & 194 & 1 & 13 & 19 & 4.500 & -217 \\
\hline 2 & 4 & 10 & 4.500 & 144 & 1 & 15 & 21 & 4.500 & -206 \\
\hline 2 & 3 & 9 & 4.500 & 140 & 1 & 14 & 20 & 4.500 & -206 \\
\hline 2 & 1 & 13 & 9.000 & 165 & 2 & 13 & 25 & 9.000 & -241 \\
\hline 2 & 5 & 11 & 4.500 & 138 & 2 & 16 & 28 & 9.000 & -231 \\
\hline 2 & 3 & 15 & 9.000 & 161 & 2 & 17 & 29 & 9.000 & -230 \\
\hline 2 & 2 & 8 & 4.500 & 130 & 1 & 9 & 21 & 9.000 & -223 \\
\hline 1 & 3 & 9 & 4.500 & 129 & 1 & 8 & 20 & 9.000 & -214 \\
\hline 1 & 5 & 11 & 4.500 & 124 & 1 & 16 & 22 & 4.500 & -180 \\
\hline 2 & 2 & 14 & 9.000 & 141 & 1 & 17 & 23 & 4.500 & -179 \\
\hline 1 & 4 & 10 & 4.500 & 116 & 2 & 15 & 27 & 9.000 & -204 \\
\hline 2 & 1 & 7 & 4.501 & 110 & 1 & 7 & 19 & 9.000 & -202 \\
\hline 1 & 2 & 8 & 4.500 & 107 & 2 & 16 & 22 & 4.500 & -169 \\
\hline 1 & 1 & 7 & 4.501 & 100 & 2 & 15 & 21 & 4.500 & -167 \\
\hline
\end{tabular}

0 of 200 Single-axis measurements exceed the Axial Allowable Deviation. The following data are an estimate of the CMM axial point-to-point errors:

$\mathrm{X}$ axis: average point-to-point error is $-4.6 \mathrm{ppm}$.

$\mathrm{Y}$ axis: average point-to-point error is $-5.7 \mathrm{ppm}$. 
Cordax data taken with both positions analyzed. No corrections applied.

Inspected by XXX Department XXX Inspection Date: 01-25-1996

The distances are in inches and deviations in microinches.

Planar Data $\quad$ Performance Specification $=+/-(0.00035$ inch $+25 \mathrm{ppm})$

\begin{tabular}{|c|c|c|c|c|c|}
\hline Inch Groups & $\leq 5$ & $\underline{5-6}$ & $\underline{6-10}$ & $\underline{10-12}$ & $\underline{12-17}$ \\
\hline Number measured distances & 40 & 40 & 94 & 78 & 156 \\
\hline Average absolute deviation & 92 & 72 & 121 & 118 & 115 \\
\hline Average deviation & -14 & -34 & -47 & -64 & -75 \\
\hline Std dev over work zone & 116 & 67 & 143 & 146 & 128 \\
\hline Std dev of multiple runs & 23 & 18 & 26 & 26 & 32 \\
\hline Radial bias of standard & 6 & 6 & 7 & 7 & 8 \\
\hline Std dev of the standard & 17 & 18 & 21 & 23 & 25 \\
\hline Uncertainty of single run & 300 & 202 & 379 & 382 & 352 \\
\hline Uncertainty of three runs & 298 & 200 & 377 & 379 & 348 \\
\hline Allowable deviation & 463 & 490 & 575 & 630 & 688 \\
\hline
\end{tabular}

These data are the 15 most positive and 15 most negative deviations with their ball plate position, sphere pair and nominal distance; respectively ranked as a percentage of the Planar allowable deviation.

\begin{tabular}{|c|c|c|c|c|c|c|c|c|c|}
\hline Position & \multicolumn{2}{|c|}{ Spheres } & Distance & Deviation & Position & \multicolumn{2}{|c|}{ Spheres } & Distance & Deviation \\
\hline 2 & 3 & 10 & 7.184 & 273 & 2 & 13 & 20 & 7.184 & -434 \\
\hline 1 & 3 & 10 & 7.184 & 260 & 2 & 7 & 20 & 10.600 & -416 \\
\hline 2 & 3 & 16 & 10.600 & 296 & 1 & 13 & 20 & 7.184 & -357 \\
\hline 2 & 4 & 16 & 9.000 & 202 & 2 & 13 & 21 & 12.070 & -439 \\
\hline 2 & 21 & 28 & 7.184 & 186 & 2 & 7 & 21 & 14.368 & -476 \\
\hline 2 & 2 & 13 & 10.600 & 211 & 2 & 13 & 26 & 10.600 & -406 \\
\hline 2 & 5 & 17 & 9.000 & 194 & 2 & 16 & 23 & 7.184 & -346 \\
\hline 1 & 2 & 10 & 12.071 & 210 & 1 & 7 & 20 & 10.600 & -382 \\
\hline 1 & 3 & 16 & 10.600 & 198 & 1 & 7 & 21 & 14.368 & -415 \\
\hline 2 & 2 & 16 & 14.368 & 222 & 2 & 13 & 27 & 14.368 & -408 \\
\hline 2 & 4 & 10 & 4.500 & 144 & 2 & 16 & 29 & 10.600 & -347 \\
\hline 2 & 5 & 16 & 10.600 & 190 & 2 & 14 & 21 & 7.184 & -294 \\
\hline 2 & 3 & 9 & 4.500 & 140 & 1 & 10 & 23 & 10.599 & -339 \\
\hline 2 & 5 & 11 & 4.500 & 138 & 1 & 16 & 23 & 7.184 & -288 \\
\hline 2 & 2 & 10 & 12.071 & 193 & 1 & 13 & 21 & 12.070 & -353 \\
\hline
\end{tabular}

0 of 6001 and 2 Axis Measurements exceed the Planar Allowable Deviation. The following data are an estimate of the CMM planar squareness errors: The indicated XY plane squareness is 7.0 ( 1.45 arcseconds).

* May be affected by yaw, pitch, roll, and straightness of the included axes. 
Cordax data taken with both positions analyzed. No corrections applied.

Inspected by XXX Department XXX Inspection Date: 01-25-1996

The distances are in inches and deviations in microinches.

Spatial Data $\quad$ Performance Specification $=+/-(0.00035$ inch $+30 \mathrm{ppm})$

$\begin{array}{lrrrrrrrr}\quad \text { Inch Groups } & \leq 6 & \frac{6-10}{10} & \underline{10-12} & \underline{1214} & \underline{14-17} & \underline{1719} & \underline{1924} & \frac{24}{32} \\ \text { Number measured distances } & 80 & 94 & 78 & 68 & 88 & 82 & 78 & 32 \\ \text { Average absolute deviation } & 82 & 121 & 118 & 110 & 118 & 100 & 122 & 148 \\ \text { Average deviation } & -24 & -47 & -64 & -60 & -86 & -73 & -104 & -139 \\ \text { Std dev over work zone } & 95 & 143 & 146 & 125 & 130 & 107 & 112 & 129 \\ \text { Std dev of multiple runs } & 21 & 26 & 26 & 30 & 33 & 33 & 34 & 39 \\ \text { Radial bias of standard } & 6 & 6 & 7 & 7 & 8 & 8 & 9 & 10 \\ \text { Std dev of the standard } & 17 & 19 & 22 & 23 & 25 & 28 & 30 & 34 \\ \text { Uncertainty of single run } & 255 & 379 & 382 & 340 & 360 & 303 & 341 & 404 \\ \text { Uncertainty of three runs } & 253 & 377 & 379 & 337 & 356 & 298 & 336 & 399 \\ \text { Allowable deviation } & 485 & 566 & 668 & 712 & 782 & 872 & 922 & 1074\end{array}$

These data are the 15 most positive and 15 most negative deviations with their ball plate position, sphere pair and nominal distance; respectively ranked as a percentage of the Spatial allowable deviation.

\begin{tabular}{|c|c|c|c|c|c|c|c|c|c|}
\hline Position & \multicolumn{2}{|c|}{ Spheres } & Distance & Deviation & Position & \multicolumn{2}{|c|}{ Spheres } & Distance & Deviation \\
\hline 2 & 3 & 10 & 7.184 & 273 & 2 & 13 & 20 & 7.184 & -434 \\
\hline 1 & 3 & 10 & 7.184 & 260 & 1 & 13 & 20 & 7.184 & -357 \\
\hline 2 & 3 & 16 & 10.600 & 296 & 2 & 7 & 20 & 10.600 & -416 \\
\hline 2 & 21 & 28 & 7.184 & 186 & 2 & 13 & 21 & 12.070 & -439 \\
\hline 2 & 4 & 16 & 9.000 & 202 & 2 & 16 & 23 & 7.184 & -346 \\
\hline 2 & 2 & 13 & 10.600 & 211 & 2 & 7 & 21 & 14.368 & -476 \\
\hline 2 & 5 & 17 & 9.000 & 194 & 2 & 13 & 26 & 10.600 & -406 \\
\hline 2 & 4 & 10 & 4.500 & 144 & 1 & 7 & 20 & 10.600 & -382 \\
\hline 1 & 3 & 16 & 10.600 & 198 & 1 & 7 & 21 & 14.368 & -415 \\
\hline 1 & 2 & 10 & 12.071 & 210 & 2 & 13 & 27 & 14.368 & -408 \\
\hline 2 & 3 & 9 & 4.500 & 140 & 2 & 16 & 29 & 10.600 & -347 \\
\hline 2 & 5 & 11 & 4.500 & 138 & 2 & 14 & 21 & 7.184 & -294 \\
\hline 2 & 5 & 16 & 10.600 & 190 & 1 & 16 & 23 & 7.184 & -288 \\
\hline 2 & 2 & 16 & 14.368 & 222 & 1 & 10 & 23 & 10.599 & -339 \\
\hline 2 & 2 & 10 & 12.071 & 193 & 1 & 13 & 21 & 12.070 & -353 \\
\hline
\end{tabular}

0 of 600 Total Radial Measurements exceed the Spatial Allowable Deviation. 
LDDM data taken with ball plate on machine table. No corrections applied.

$$
16000 \text { Ball plate Exp. date: 08-25-96 }
$$

Software: Name PC1808, ID\# CS-09P-144, Issue A, Revision 06/02/95

Inspected by XXX Department XXX Inspection Date: 01-25-1996

The distances are in inches and deviations in microinches.

Axial Data Performance Specification $=+/-(0.00035$ inch $+17 \mathrm{ppm})$

\begin{tabular}{lrrr}
\multicolumn{1}{c}{ Inch Groups } & $\leq 5$ & $5-12$ & $\geq 12$ \\
Number measured distances & 20 & 50 & 30 \\
Average absolute deviation & 224 & 191 & 463 \\
Average deviation & -224 & -188 & -463 \\
Std dev over work zone & 79 & 206 & 333 \\
Std dev of multiple runs & 50 & 38 & 48 \\
Radial bias of standard & 6 & 7 & 8 \\
Std dev of the standard & 17 & 21 & 25 \\
Uncertainty of single run & 484 & 566 & 1144 \\
Uncertainty of three runs & 477 & 562 & 1141 \\
Allowable deviation & 427 & 503 & 580
\end{tabular}

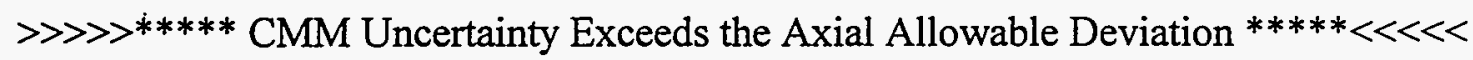

These data are the 15 most positive and 15 most negative deviations with their ball plate position, sphere pair and nominal distance; respectively ranked as a percentage of the Axial allowable deviation.

\begin{tabular}{|c|c|c|c|c|c|c|c|c|c|}
\hline Position & \multicolumn{2}{|c|}{ Spheres } & Distance & Deviation & Position & $\underline{\mathrm{Sph}}$ & & Distance & Deviation \\
\hline 1 & 1 & 2 & 5.601 & 57 & 1 & 1 & $\overline{25}$ & 18.000 & -939 \\
\hline 1 & 7 & 8 & 5.600 & 6 & 1 & 2 & 26 & 18.000 & -924 \\
\hline 1 & 13 & 14 & 5.600 & 3 & 1 & 10 & 28 & 13.500 & -806 \\
\hline 1 & 19 & 20 & 5.600 & -9 & 1 & 3 & 27 & 18.000 & -897 \\
\hline 1 & 1 & 3 & 11.201 & -11 & 1 & 11 & 29 & 13.500 & -772 \\
\hline 1 & 7 & 9 & 11.200 & -28 & 1 & 7 & 25 & 13.500 & -767 \\
\hline 1 & 13 & 15 & 11.200 & -29 & 1 & 1 & 19 & 13.500 & -765 \\
\hline 1 & 14 & 15 & 5.599 & -32 & 1 & 4 & 28 & 18.000 & -863 \\
\hline 1 & 8 & 9 & 5.600 & -34 & 1 & 5 & 29 & 18.000 & -862 \\
\hline 1 & 28 & 29 & 5.600 & -36 & 1 & 8 & 26 & 13.500 & -758 \\
\hline 1 & 10 & 11 & 5.599 & -40 & 1 & 9 & 27 & 13.500 & -710 \\
\hline 1 & 1 & 4 & 16.800 & -59 & 1 & 3 & 21 & 13.500 & -708 \\
\hline 1 & 25 & 26 & 5.600 & -44 & 1 & 2 & 20 & 13.500 & -697 \\
\hline 1 & 19 & 21 & 11.200 & -56 & 1 & 7 & 19 & 9.000 & -593 \\
\hline 1 & 21 & 22 & 5.600 & -47 & 1 & 16 & 28 & 9.000 & -592 \\
\hline
\end{tabular}

24 of 100 Single-axis measurements exceed the Axial Allowable Deviation.

The following data are an estimate of the CMM axial point-to-point errors:

$\mathrm{X}$ axis: average point-to-point error is $-7.6 \mathrm{ppm}$.

$\mathrm{Y}$ axis: average point-to-point error is $-51.8 \mathrm{ppm}$. 
LDDM data taken with ball plate on machine table. No corrections applied.

Inspected by XXX $\quad$ Department XXX Inspection Date: 01-25-1996

The distances are in inches and deviations in microinches.

Planar Data $\quad$ Performance Specification $=+/-(0.00035$ inch $+25 \mathrm{ppm})$

\begin{tabular}{|c|c|c|c|c|c|c|}
\hline Inch Groups & $\leq \underline{5}$ & $\underline{5-6}$ & $\underline{6-10}$ & $\underline{10-12}$ & $12-17$ & $\geq 17$ \\
\hline Number measured distances & 20 & 20 & 47 & 39 & 78 & \\
\hline Average absolute deviation & 224 & 46 & 271 & 299 & 389 & \\
\hline Average deviation & -224 & -40 & -271 & -299 & -387 & \\
\hline Std dev over work zone & 79 & 34 & 188 & 205 & 262 & \\
\hline Std dev of multiple runs & 50 & 27 & 46 & 44 & 47 & \\
\hline Radial bias of standard & 6 & 6 & 7 & 7 & 8 & \\
\hline Std dev of the standard & 17 & 18 & 21 & 23 & 25 & \\
\hline Uncertainty of single run & 484 & 128 & 666 & 730 & 942 & \\
\hline Uncertainty of three runs & 477 & 121 & 662 & 726 & 939 & \\
\hline Allowable deviation & 463 & 490 & 575 & 630 & 688 & \\
\hline
\end{tabular}

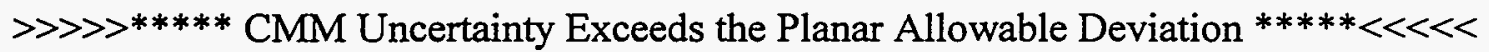

These data are the 15 most positive and 15 most negative deviations with their ball plate position, sphere pair and nominal distance; respectively ranked as a percentage of the Planar allowable deviation.

\begin{tabular}{|c|c|c|c|c|c|c|c|c|c|}
\hline Position & \multicolumn{2}{|c|}{ Spheres } & Distance & Deviation & Position & \multicolumn{2}{|c|}{ Spheres } & Distance & Deviation \\
\hline 1 & 1 & 2 & 5.601 & 57 & 1 & 1 & 26 & 18.852 & -1043 \\
\hline 1 & 15 & 19 & 12.070 & 56 & 1 & 7 & 26 & 14.615 & -896 \\
\hline 1 & 8 & 13 & 7.184 & 9 & 1 & 10 & 29 & 14.615 & -874 \\
\hline 1 & 7 & 8 & 5.600 & 6 & 1 & 1 & 20 & 14.616 & -841 \\
\hline 1 & 13 & 14 & 5.600 & 3 & 1 & 1 & 25 & 18.000 & -939 \\
\hline 1 & 3 & 10 & 7.184 & 0 & 1 & 10 & 28 & 13.500 & -806 \\
\hline 1 & 9 & 13 & 12.070 & -6 & 1 & 10 & 23 & 10.599 & -715 \\
\hline 1 & 19 & 20 & 5.600 & -9 & 1 & 7 & 20 & 10.600 & -711 \\
\hline 1 & 1 & 3 & 11.201 & -11 & 1 & 2 & 26 & 18.000 & -924 \\
\hline 1 & 14 & 19 & 7.184 & -12 & 1 & 3 & 26 & 18.851 & -925 \\
\hline 1 & 1 & 10 & 17.393 & -31 & 1 & 4 & 29 & 18.851 & -923 \\
\hline 1 & 17 & 19 & 22.847 & -37 & 1 & 11 & 29 & 13.500 & -772 \\
\hline 1 & 17 & 22 & 7.184 & -23 & 1 & 3 & 27 & 18.000 & -897 \\
\hline 1 & 7 & 9 & 11.200 & -28 & 1 & 7 & 25 & 13.500 & -767 \\
\hline 1 & 1 & 9 & 12.071 & -30 & 1 & 1 & 19 & 13.500 & -765 \\
\hline
\end{tabular}

31 of 3001 and 2 Axis Measurements exceed the Planar Allowable Deviation.

The following data are an estimate of the CMM planar squareness errors:

The indicated $X Y$ plane squareness is 7.7 (1.58 arcseconds).

* May be affected by yaw, pitch, roll, and straightness of the included axes. 
LDDM data taken with ball plate on machine table. No corrections applied.

Inspected by XXX Department XXX Inspection Date: 01-25-1996

The distances are in inches and deviations in microinches.

Spatial Data Performance Specification $=+/-(0.00035$ inch $+30 \mathrm{ppm})$

\begin{tabular}{|c|c|c|c|c|c|c|c|c|}
\hline Inch Groups & $\leq 6$ & $\underline{6-10}$ & $\underline{10-12}$ & $\underline{1214}$ & $\underline{14-17}$ & $\underline{1719}$ & $\underline{1924}$ & $\geq 2$ \\
\hline Number measured distances & 40 & 47 & 39 & 34 & 44 & 41 & 39 & 6 \\
\hline Average absolute deviation & 135 & 271 & 299 & 334 & 431 & 531 & 409 & \\
\hline Average deviation & -132 & -271 & -299 & -331 & -431 & -531 & -409 & -5 \\
\hline Std dev over work zone & 111 & 188 & 205 & 280 & 242 & 316 & 244 & \\
\hline Std dev of multiple runs & 40 & 46 & 44 & 47 & 48 & 51 & 48 & \\
\hline Radial bias of standard & 6 & 6 & 7 & 7 & 8 & 8 & 9 & \\
\hline Std dev of the standard & 17 & 19 & 22 & 23 & 25 & 28 & 30 & \\
\hline Uncertainty of single run & 358 & 666 & 730 & 877 & 992 & 1240 & 957 & \\
\hline Uncertainty of three runs & 352 & 661 & 726 & 873 & 989 & 1237 & 954 & 11 \\
\hline Allowable deviation & 485 & 566 & 668 & 712 & 782 & 872 & 922 & \\
\hline
\end{tabular}

These data are the 15 most positive and 15 most negative deviations with their ball plate position, sphere pair and nominal distance; respectively ranked as a percentage of the Spatial allowable deviation.

\begin{tabular}{|c|c|c|c|c|c|c|c|c|c|}
\hline Position & \multicolumn{2}{|c|}{ Spheres } & Distance & Deviation & Position & \multicolumn{2}{|c|}{ Spheres } & Distance & Deviation \\
\hline 1 & 1 & 2 & 5.601 & 57 & 1 & 1 & 26 & 18.852 & -1043 \\
\hline 1 & 15 & 19 & 12.070 & 56 & 1 & 7 & 26 & 14.615 & -896 \\
\hline 1 & 8 & 13 & 7.184 & 9 & 1 & 10 & 29 & 14.615 & -874 \\
\hline 1 & 7 & 8 & 5.600 & 6 & 1 & 10 & 23 & 10.599 & -715 \\
\hline 1 & 13 & 14 & 5.600 & 3 & 1 & 1 & 20 & 14.616 & -841 \\
\hline 1 & 3 & 10 & 7.184 & 0 & 1 & 10 & 28 & 13.500 & -806 \\
\hline 1 & 9 & 13 & 12.070 & -6 & 1 & 7 & 20 & 10.600 & -711 \\
\hline 1 & 1 & 3 & 11.201 & -11 & 1 & 1 & 25 & 18.000 & -939 \\
\hline 1 & 19 & 20 & 5.600 & -9 & 1 & 2 & 26 & 18.000 & -924 \\
\hline 1 & 14 & 19 & 7.184 & -12 & 1 & 11 & 29 & 13.500 & -772 \\
\hline 1 & 17 & 19 & 22.847 & -37 & 1 & 7 & 25 & 13.500 & -767 \\
\hline 1 & 1 & 10 & 17.393 & -31 & 1 & 1 & 19 & 13.500 & -765 \\
\hline 1 & 17 & 22 & 7.184 & -23 & 1 & 3 & 26 & 18.851 & -925 \\
\hline 1 & 7 & 9 & 11.200 & -28 & 1 & 4 & 29 & 18.851 & -923 \\
\hline 1 & 1 & 9 & 12.071 & -30 & 1 & 3 & 27 & 18.000 & -897 \\
\hline
\end{tabular}

16 of 300 Total Radial Measurements exceed the Spatial Allowable Deviation. 
Page 1 of 3

LDDM data taken with ball plate raised 9.5 inches above machine table. No corrections applied.

$$
16000 \text { Ball plate Exp. date: } 08-25-96
$$

Software: Name PC1808, ID\# CS-09P-144, Issue A, Revision 06/02/95

Inspected by XXX Department XXX Inspection Date: 01-25-1996

The distances are in inches and deviations in microinches.

Axial Data Performance Specification $=+/-(0.00035$ inch $+17 \mathrm{ppm})$

\begin{tabular}{|c|c|c|c|}
\hline Inch Groups & $\leq 5$ & $\underline{5-12}$ & $\geq 12$ \\
\hline Number measured distances & $\overline{20}$ & 50 & 30 \\
\hline Average absolute deviation & 234 & 192 & 474 \\
\hline Average deviation & -234 & -191 & -474 \\
\hline Std dev over work zone & 58 & 208 & 347 \\
\hline Std dev of multiple runs & 29 & 27 & 25 \\
\hline Radial bias of standard & 6 & 7 & 8 \\
\hline Std dev of the standard & 17 & 21 & 25 \\
\hline Uncertainty of single run & 485 & 570 & 1177 \\
\hline Uncertainty of three runs & 482 & 568 & 1176 \\
\hline ov & 427 & 503 & 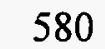 \\
\hline
\end{tabular}

>>>>***** CMM Uncertainty Exceeds the Axial Allowable Deviation $* * * * *<<<<<$

These data are the 15 most positive and 15 most negative deviations with their ball plate position, sphere pair and nominal distance; respectively ranked as a percentage of the Axial allowable deviation.

\begin{tabular}{|c|c|c|c|c|c|c|c|c|c|}
\hline Position & \multicolumn{2}{|c|}{ Spheres } & Distance & Deviation & Position & \multicolumn{2}{|c|}{ Spheres } & Distance & Deviation \\
\hline 1 & 13 & 14 & 5.600 & 16 & 1 & 2 & 26 & 18.000 & -961 \\
\hline 1 & 8 & 9 & 5.600 & 10 & 1 & 1 & 25 & 18.000 & -940 \\
\hline 1 & 13 & 15 & 11.200 & -2 & 1 & 5 & 29 & 18.000 & -935 \\
\hline 1 & 19 & 20 & 5.600 & -10 & 1 & 4 & 28 & 18.000 & -933 \\
\hline 1 & 2 & 3 & 5.600 & -12 & 1 & 3 & 27 & 18.000 & -904 \\
\hline 1 & 7 & 9 & 11.200 & -18 & 1 & 8 & 26 & 13.500 & -775 \\
\hline 1 & 1 & 2 & 5.601 & -18 & 1 & 2 & 20 & 13.500 & -773 \\
\hline 1 & 14 & 15 & 5.599 & -19 & 1 & 1 & 19 & 13.500 & -765 \\
\hline 1 & 26 & 27 & 5.600 & -19 & 1 & 10 & 28 & 13.500 & -750 \\
\hline 1 & 20 & 21 & 5.600 & -22 & 1 & 9 & 27 & 13.500 & -741 \\
\hline 1 & 1 & 3 & 11.201 & -30 & 1 & 7 & 25 & 13.500 & -739 \\
\hline 1 & 19 & 21 & 11.200 & -32 & 1 & 3 & 21 & 13.500 & -733 \\
\hline 1 & 7 & 8 & 5.600 & -28 & 1 & 11 & 29 & 13.500 & -730 \\
\hline 1 & 28 & 29 & 5.600 & -41 & 1 & 5 & 23 & 13.500 & -728 \\
\hline 1 & 8 & 10 & 11.200 & -55 & 1 & 4 & 22 & 13.500 & -718 \\
\hline
\end{tabular}

23 of 100 Single-axis measurements exceed the Axial Allowable Deviation.

The following data are an estimate of the CMM axial point-to-point errors:

$\mathrm{X}$ axis: average point-to-point error is $-7.5 \mathrm{ppm}$.

$Y$ axis: average point-to-point error is $-53.6 \mathrm{ppm}$. 
LDDM data taken with ball plate raised 9.5 inches above machine table. No corrections applied.

Inspected by XXX Department XXX Inspection Date: 01-25-1996

The distances are in inches and deviations in microinches.

Planar Data Performance Specification $=+/-(0.00035$ inch $+25 \mathrm{ppm})$

\begin{tabular}{|c|c|c|c|c|c|c|}
\hline Inch Groups & $\leq \underline{5}$ & $\underline{5-6}$ & $\underline{6-10}$ & $10-12$ & $12-17$ & 17 \\
\hline Number measured distances & 20 & 20 & 47 & 39 & 78 & \\
\hline Average absolute deviation & 234 & 44 & 279 & 306 & 393 & \\
\hline Average deviation & -234 & -42 & -279 & -306 & -393 & \\
\hline Std dev over work zone & 58 & 31 & 172 & 196 & 264 & \\
\hline Std dev of multiple runs & 29 & 24 & 28 & 31 & 26 & \\
\hline Radial bias of standard & 6 & 6 & 7 & 7 & 8 & \\
\hline Std dev of the standard & 17 & 18 & 21 & 23 & 25 & \\
\hline Uncertainty of single run & 485 & 121 & 659 & 729 & 950 & \\
\hline Uncertainty of three runs & 482 & 115 & 658 & 727 & 949 & \\
\hline Allowable deviation & 463 & 490 & 575 & 630 & 688 & \\
\hline
\end{tabular}

$\gg \gg \gg>* * * * *$ CMM Uncertainty Exceeds the Planar Allowable Deviation $* * * * *<<<<$

These data are the 15 most positive and 15 most negative deviations with their ball plate position, sphere pair and nominal distance; respectively ranked as a percentage of the Planar allowable deviation.

\begin{tabular}{|c|c|c|c|c|c|c|c|c|c|}
\hline Position & \multicolumn{2}{|c|}{ Spheres } & Distance & Deviation & Position & \multicolumn{2}{|c|}{ Spheres } & Distance & Deviation \\
\hline 1 & 13 & 14 & 5.600 & 16 & 1 & 1 & 26 & 18.852 & -1004 \\
\hline 1 & 8 & 9 & 5.600 & 10 & 1 & 2 & 26 & 18.000 & -961 \\
\hline 1 & 15 & 19 & 12.070 & 12 & 1 & 1 & 25 & 18.000 & -940 \\
\hline 1 & 13 & 15 & 11.200 & -2 & 1 & 5 & 29 & 18.000 & -935 \\
\hline 1 & 19 & 20 & 5.600 & -10 & 1 & 4 & 28 & 18.000 & -933 \\
\hline 1 & 2 & 3 & 5.600 & -12 & 1 & 7 & 26 & 14.615 & -827 \\
\hline 1 & 7 & 9 & 11.200 & -18 & 1 & 1 & 20 & 14.616 & -824 \\
\hline 1 & 1 & 9 & 12.071 & -20 & 1 & 4 & 29 & 18.851 & -933 \\
\hline 1 & 2 & 10 & 12.071 & -20 & 1 & 4 & 27 & 18.851 & -931 \\
\hline 1 & 1 & 2 & 5.601 & -18 & 1 & 3 & 27 & 18.000 & -904 \\
\hline 1 & 14 & 15 & 5.599 & -19 & 1 & 8 & 26 & 13.500 & -775 \\
\hline 1 & 26 & 27 & 5.600 & -19 & 1 & 2 & 20 & 13.500 & -773 \\
\hline 1 & 20 & 21 & 5.600 & -22 & 1 & 1 & 19 & 13.500 & -765 \\
\hline 1 & 14 & 19 & 7.184 & -25 & 1 & 10 & 29 & 14.615 & -789 \\
\hline 1 & 1 & 3 & 11.201 & -30 & 1 & 3 & 26 & 18.851 & -902 \\
\hline
\end{tabular}

34 of 3001 and 2 Axis Measurements exceed the Planar Allowable Deviation. The following data are an estimate of the CMM planar squareness errors: The indicated XY plane squareness is 4.9 (1.01 arcseconds).

* May be affected by yaw, pitch, roll, and straightness of the included axes. 
Page 3 of 3

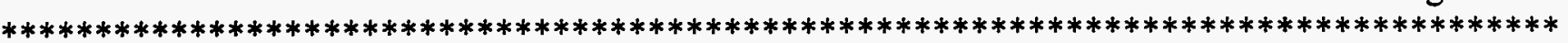

LDDM CALIBRATION WORKSHEET

$*$

LDDM data taken with ball plate raised 9.5 inches above machine table. No corrections applied. Inspected by XXX Department XXX Inspection Date: 01-25-1996

The distances are in inches and deviations in microinches.

Spatial Data $\quad$ Performance Specification $=+/-(0.00035$ inch $+30 \mathrm{ppm})$

\begin{tabular}{|c|c|c|c|c|c|c|c|c|}
\hline Inch Groups & $\leq 6$ & $\underline{6-10}$ & $\underline{10-12}$ & 1214 & $\underline{14-17}$ & $\underline{1719}$ & 1924 & $\geq 24$ \\
\hline Number measured distances & 40 & 47 & 39 & 34 & 44 & 41 & 39 & \\
\hline Average absolute deviation & 139 & 279 & 306 & 334 & 439 & 544 & 415 & \\
\hline Average deviation & -138 & -279 & -306 & -333 & -439 & -544 & -415 & \\
\hline over work zone & 107 & 172 & 196 & 284 & 240 & 326 & 243 & \\
\hline $\mathrm{d}$ dev of multiple runs & 26 & 28 & 31 & 27 & 26 & 22 & 24 & \\
\hline adial bias of standard & 6 & 6 & 7 & 7 & 0 & 8 & 9 & \\
\hline $\mathrm{d}$ dev of the standard & 17 & 19 & 22 & 23 & 25 & 28 & 30 & \\
\hline acertainty of single run & 356 & 659 & 729 & 879 & 1004 & 1270 & 965 & 11 \\
\hline acertainty of three runs & 353 & 658 & 727 & 878 & 1003 & 1269 & 964 & \\
\hline lowable deviation & 485 & 566 & 668 & 712 & 782 & 872 & 922 & \\
\hline
\end{tabular}

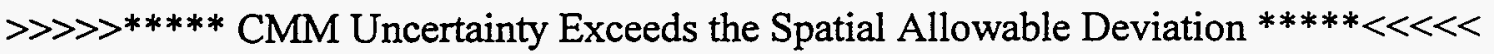

These data are the 15 most positive and 15 most negative deviations with their ball plate position, sphere pair and nominal distance; respectively ranked as a percentage of the Spatial allowable deviation.

\begin{tabular}{|c|c|c|c|c|c|c|c|c|c|}
\hline Position & \multicolumn{2}{|c|}{ Spheres } & Distance & Deviation & Position & \multicolumn{2}{|c|}{$\underline{\text { Spheres }}$} & Distance & Deviation \\
\hline 1 & 13 & 14 & 5.600 & 16 & 1 & 1 & 26 & 18.852 & -1004 \\
\hline 1 & 8 & 9 & 5.600 & 10 & 1 & 2 & 26 & 18.000 & -961 \\
\hline 1 & 15 & 19 & 12.070 & 12 & 1 & 1 & 25 & 18.000 & -940 \\
\hline 1 & 13 & 15 & 11.200 & -2 & 1 & 5 & 29 & 18.000 & -935 \\
\hline 1 & 19 & 20 & 5.600 & -10 & 1 & 7 & 26 & 14.615 & -827 \\
\hline 1 & 2 & 3 & 5.600 & -12 & 1 & 4 & 28 & 18.000 & -933 \\
\hline 1 & 7 & 9 & 11.200 & -18 & 1 & 1 & 20 & 14.616 & -824 \\
\hline 1 & 1 & 9 & 12.071 & -20 & 1 & 8 & 26 & 13.500 & -775 \\
\hline 1 & 2 & 10 & 12.071 & -20 & 1 & 2 & 20 & 13.500 & -773 \\
\hline 1 & 1 & 2 & 5.601 & -18 & 1 & 4 & 29 & 18.851 & -933 \\
\hline 1 & 14 & 15 & 5.599 & -19 & 1 & 4 & 27 & 18.851 & -931 \\
\hline 1 & 26 & 27 & 5.600 & -19 & 1 & 3 & 27 & 18.000 & -904 \\
\hline 1 & 20 & 21 & 5.600 & -22 & 1 & 1 & 19 & 13.500 & -765 \\
\hline 1 & 1 & 3 & 11.201 & -30 & 1 & 10 & 29 & 14.615 & -789 \\
\hline 1 & 14 & 19 & 7.184 & -25 & 1 & 10 & 28 & 13.500 & -750 \\
\hline
\end{tabular}

14 of 300 Total Radial Measurements exceed the Spatial Allowable Deviation. 
LDDM data taken with both positions analyzed. No corrections applied.

\begin{tabular}{llll}
\hline \multicolumn{1}{c}{16000 Ball plate Exp. date: $08-25-96$} \\
Software: $\quad$ Name PC1808, & ID\# CS-09P-144, Issue A, Revision 06/02/95 \\
\hline Inspected by XXX Department XXX Inspection Date: $01-25-1996$
\end{tabular}
The distances are in inches and deviations in microinches.

Axial Data Performance Specification $=+/-(0.00035$ inch $+17 \mathrm{ppm})$

\begin{tabular}{|c|c|c|c|}
\hline Inch Groups & $\leq 5$ & $\underline{5-12}$ & $\geq 12$ \\
\hline Number measured distances & $\overline{40}$ & 100 & 60 \\
\hline Average absolute deviation & 229 & 191 & 468 \\
\hline Average deviation & -229 & -189 & -468 \\
\hline Std dev over work zone & 68 & 206 & 337 \\
\hline Std dev of multiple runs & 41 & 33 & 8 \\
\hline Radial bias of standard & 6 & 7 & 8 \\
\hline Std dev of the standard & 17 & 21 & 25 \\
\hline Uncertainty of single run & 484 & 566 & 1157 \\
\hline Uncertainty of three runs & 479 & 564 & 1156 \\
\hline or & 427 & 503 & \\
\hline
\end{tabular}

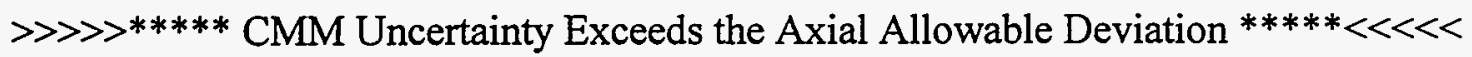

These data are the 15 most positive and 15 most negative deviations with their ball plate position, sphere pair and nominal distance; respectively ranked as a percentage of the Axial allowable deviation.

\begin{tabular}{|c|c|c|c|c|c|c|c|c|c|}
\hline Position & \multicolumn{2}{|c|}{ Spheres } & Distance & Deviation & Position & \multicolumn{2}{|c|}{ Spheres } & Distance & Deviation \\
\hline 1 & 1 & 2 & 5.601 & 57 & 2 & 2 & 26 & 18.000 & -961 \\
\hline 2 & 13 & 14 & 5.600 & 16 & 2 & 1 & 25 & 18.000 & -940 \\
\hline 2 & 8 & 9 & 5.600 & 10 & 1 & 1 & 25 & 18.000 & -939 \\
\hline 1 & 7 & 8 & 5.600 & 6 & 2 & 5 & 29 & 18.000 & -935 \\
\hline 1 & 13 & 14 & 5.600 & 3 & 2 & 4 & 28 & 18.000 & -933 \\
\hline 2 & 13 & 15 & 11.200 & -2 & 1 & 2 & 26 & 18.000 & -924 \\
\hline 1 & 19 & 20 & 5.600 & -9 & 1 & 10 & 28 & 13.500 & -806 \\
\hline 1 & 1 & 3 & 11.201 & -11 & 2 & 3 & 27 & 18.000 & -904 \\
\hline 2 & 19 & 20 & 5.600 & -10 & 1 & 3 & 27 & 18.000 & -897 \\
\hline 2 & 2 & 3 & 5.600 & -12 & 2 & 8 & 26 & 13.500 & -775 \\
\hline 2 & 7 & 9 & 11.200 & -18 & 2 & 2 & 20 & 13.500 & -773 \\
\hline 2 & 1 & 2 & 5.601 & -18 & 1 & 11 & 29 & 13.500 & -772 \\
\hline 2 & 14 & 15 & 5.599 & -19 & 1 & 7 & 25 & 13.500 & -767 \\
\hline 2 & 26 & 27 & 5.600 & -19 & 1 & 1 & 19 & 13.500 & -765 \\
\hline 2 & 20 & 21 & 5.600 & -22 & 2 & 1 & 19 & 13.500 & -765 \\
\hline
\end{tabular}

47 of 200 Single-axis measurements exceed the Axial Allowable Deviation.

The following data are an estimate of the CMM axial point-to-point errors:

$\mathrm{X}$ axis: average point-to-point error is $-7.5 \mathrm{ppm}$.

$Y$ axis: average point-to-point error is $-52.7 \mathrm{ppm}$. 
LDDM data taken with both positions analyzed. No corrections applied.

Inspected by XXX Department XXX Inspection Date: 01-25-1996

The distances are in inches and deviations in microinches.

Planar Data Performance Specification $=+/-(0.00035$ inch $+25 \mathrm{ppm})$

\begin{tabular}{|c|c|c|c|c|c|c|}
\hline Inch Groups & $\leq 5$ & $\underline{5-6}$ & $\underline{6-10}$ & $\underline{10-12}$ & $\underline{12-17}$ & $\geq 17$ \\
\hline Number measured distances & 40 & 40 & 94 & 78 & 156 & 192 \\
\hline Average absolute deviation & 229 & 45 & 275 & 302 & 391 & 487 \\
\hline Average deviation & -229 & -41 & -275 & -302 & -390 & -487 \\
\hline Std dev over work zone & 68 & 32 & 179 & 199 & 262 & 279 \\
\hline Std dev of multiple runs & 41 & 25 & 38 & 38 & 38 & 39 \\
\hline Radial bias of standard & 6 & 6 & 7 & 7 & 8 & 9 \\
\hline Std dev of the standard & 17 & 18 & 21 & 23 & 25 & 29 \\
\hline Uncertainty of single run & 484 & 125 & 662 & 728 & 945 & 1125 \\
\hline Uncertainty of three runs & 479 & 118 & 659 & 725 & 943 & 1123 \\
\hline Allowable deviation & 463 & 490 & 575 & 630 & 688 & 800 \\
\hline
\end{tabular}

$\gg \gg \gg>* * * *$ CMM Uncertainty Exceeds the Planar Allowable Deviation $* * * * *<<<<<$

These data are the 15 most positive and 15 most negative deviations with their ball plate position, sphere pair and nominal distance; respectively ranked as a percentage of the Planar allowable deviation.

\begin{tabular}{|c|c|c|c|c|c|c|c|c|c|}
\hline Position & \multicolumn{2}{|c|}{ Spheres } & Distance & Deviation & Position & \multicolumn{2}{|c|}{ Spheres } & Distance & Deviation \\
\hline 1 & 1 & 2 & 5.601 & 57 & 1 & 1 & 26 & 18.852 & -1043 \\
\hline 1 & 15 & 19 & 12.070 & 56 & 1 & 7 & 26 & 14.615 & -896 \\
\hline 2 & 13 & 14 & 5.600 & 16 & 1 & 10 & 29 & 14.615 & -874 \\
\hline 2 & 8 & 9 & 5.600 & 10 & 2 & 1 & 26 & 18.852 & -1004 \\
\hline 2 & 15 & 19 & 12.070 & 12 & 2 & 2 & 26 & 18.000 & -961 \\
\hline 1 & 8 & 13 & 7.184 & 9 & 1 & 1 & 20 & 14.616 & -841 \\
\hline 1 & 7 & 8 & 5.600 & 6 & 2 & 1 & 25 & 18.000 & -940 \\
\hline 1 & 13 & 14 & 5.600 & 3 & 1 & 1 & 25 & 18.000 & -939 \\
\hline 1 & 3 & 10 & 7.184 & -0 & 1 & 10 & 28 & 13.500 & -806 \\
\hline 2 & 13 & 15 & 11.200 & -2 & 2 & 5 & 29 & 18.000 & -935 \\
\hline 1 & 9 & 13 & 12.070 & -6 & 2 & 4 & 28 & 18.000 & -933 \\
\hline 1 & 19 & 20 & 5.600 & -9 & 1 & 10 & 23 & 10.599 & -715 \\
\hline 1 & 1 & 3 & 11.201 & -11 & 1 & 7 & 20 & 10.600 & -711 \\
\hline 2 & 19 & 20 & 5.600 & -10 & 2 & 7 & 26 & 14.615 & -827 \\
\hline 1 & 14 & 19 & 7.184 & -12 & 1 & 2 & 26 & 18.000 & -924 \\
\hline
\end{tabular}

65 of 6001 and 2 Axis Measurements exceed the Planar Allowable Deviation. The following data are an estimate of the CMM planar squareness errors:

The indicated $\mathrm{XY}$ plane squareness is 6.3 (1.29 arcseconds).

* May be affected by yaw, pitch, roll, and straightness of the included axes. 
LDDM data taken with both positions analyzed. No corrections applied.

Inspected by XXX Department XXX Inspection Date: 01-25-1996

The distances are in inches and deviations in microinches.

Spatial Data Performance Specification $=+/-(0.00035$ inch $+30 \mathrm{ppm})$

\begin{tabular}{|c|c|c|c|c|c|c|c|c|}
\hline Inch Groups & $\leq \underline{6}$ & $\underline{6-10}$ & $\underline{10-12}$ & $\underline{1214}$ & $\underline{14-17}$ & $\underline{1719}$ & $\underline{1924}$ & $\geq 24$ \\
\hline Number measured distances & 80 & 94 & 78 & 68 & 88 & 82 & 78 & 32 \\
\hline Average absolute deviation & 137 & 275 & 302 & 334 & 435 & 537 & 412 & 538 \\
\hline Average deviation & -135 & -275 & -302 & -332 & -435 & -537 & -412 & -538 \\
\hline Std dev over work zone & 108 & 179 & 199 & 280 & 240 & 319 & 242 & 213 \\
\hline Std dev of multiple runs & 34 & 38 & 38 & 38 & 38 & 39 & 38 & 42 \\
\hline Radial bias of standard & 6 & 6 & 7 & 7 & 8 & 8 & 9 & 10 \\
\hline Std dev of the standard & 17 & 19 & 22 & 23 & 25 & 28 & 30 & 34 \\
\hline Uncertainty of single run & 356 & 661 & 728 & 875 & 997 & 1253 & 959 & 1161 \\
\hline Uncertainty of three runs & 352 & 658 & 725 & 873 & 995 & 1251 & 957 & 1159 \\
\hline Allowable deviation & 485 & 566 & 668 & 712 & 782 & 872 & 922 & 1074 \\
\hline
\end{tabular}

$\gg \gg \gg>* * * * *$ CMM Uncertainty Exceeds the Spatial Allowable Deviation $* * * * *<<<<<$

These data are the 15 most positive and 15 most negative deviations with their ball plate position, sphere pair and nominal distance; respectively ranked as a percentage of the Spatial allowable deviation.

\begin{tabular}{|c|c|c|c|c|c|c|c|c|c|}
\hline Position & \multicolumn{2}{|c|}{ Spheres } & Distance & Deviation & Position & \multicolumn{2}{|c|}{ Spheres } & Distance & Deviation \\
\hline 1 & 1 & 2 & 5.601 & 57 & 1 & 1 & 26 & 18.852 & -1043 \\
\hline 1 & 15 & 19 & 12.070 & 56 & 1 & 7 & 26 & 14.615 & -896 \\
\hline 2 & 13 & 14 & 5.600 & 16 & 1 & 10 & 29 & 14.615 & -874 \\
\hline 2 & 8 & 9 & 5.600 & 10 & 2 & 1 & 26 & 18.852 & -1004 \\
\hline 2 & 15 & 19 & 12.070 & 12 & 2 & 2 & 26 & 18.000 & -961 \\
\hline 1 & 8 & 13 & 7.184 & 9 & 1 & 10 & 23 & 10.599 & -715 \\
\hline 1 & 7 & 8 & 5.600 & 6 & 1 & 1 & 20 & 14.616 & -841 \\
\hline 1 & 13 & 14 & 5.600 & 3 & 1 & 10 & 28 & 13.500 & -806 \\
\hline 1 & 3 & 10 & 7.184 & -0 & 1 & 7 & 20 & 10.600 & -711 \\
\hline 2 & 13 & 15 & 11.200 & -2 & 2 & 1 & 25 & 18.000 & -940 \\
\hline 1 & 9 & 13 & 12.070 & -6 & 1 & 1 & 25 & 18.000 & -939 \\
\hline 1 & 1 & 3 & 11.201 & -11 & 2 & 5 & 29 & 18.000 & -935 \\
\hline 1 & 19 & 20 & 5.600 & -9 & 2 & 7 & 26 & 14.615 & -827 \\
\hline 2 & 19 & 20 & 5.600 & -10 & 2 & 4 & 28 & 18.000 & -933 \\
\hline 1 & 14 & 19 & 7.184 & -12 & 2 & 1 & 20 & 14.616 & -824 \\
\hline
\end{tabular}

30 of 600 Total Radial Measurements exceed the Spatial Allowable Deviation. 
LDDM data taken with ball plate on machine table. Corrected for Angular Errors Only.

$$
16000 \text { Ball plate Exp. date: 08-25-96 }
$$

Software: Name PC1808, ID\# CS-09P-144, Issue A, Revision 06/02/95

Inspected by XXX Department XXX Inspection Date: 01-25-1996

The distances are in inches and deviations in microinches.

Axial Data Performance Specification $=+/-(0.00035$ inch $+17 \mathrm{ppm})$

\begin{tabular}{lrrr}
\multicolumn{1}{c}{ Inch Groups } & $\leq 5$ & $\underline{5-12}$ & $\geq 12$ \\
Number measured distances & 20 & 50 & 30 \\
Average absolute deviation & 122 & 139 & 292 \\
Average deviation & 113 & -2 & 73 \\
Std dev over work zone & 76 & 161 & 306 \\
Std dev of multiple runs & 86 & 72 & 66 \\
Radial bias of standard & 6 & 7 & 8 \\
Std dev of the standard & 17 & 21 & 25 \\
Uncertainty of single run & 323 & 443 & 854 \\
Uncertainty of three runs & 291 & 427 & 847 \\
Allowable deviation & 427 & 503 & 580
\end{tabular}

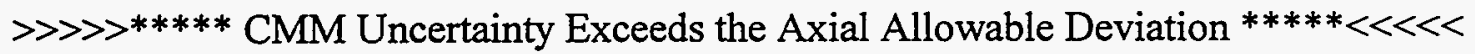

These data are the 15 most positive and 15 most negative deviations with their ball plate position, sphere pair and nominal distance; respectively ranked as a percentage of the Axial allowable deviation.

\begin{tabular}{|c|c|c|c|c|c|c|c|c|c|}
\hline Position & \multicolumn{2}{|c|}{ Spheres } & Distance & Deviation & Position & \multicolumn{2}{|c|}{ Spheres } & Distance & Deviation \\
\hline 1 & 4 & 16 & 9.000 & 392 & 1 & 2 & 5 & 16.800 & -362 \\
\hline 1 & 4 & 28 & 18.000 & 501 & 1 & 2 & 4 & 11.200 & -236 \\
\hline 1 & 3 & 27 & 18.000 & 489 & 1 & 14 & 17 & 16.800 & -277 \\
\hline 1 & 9 & 27 & 13.500 & 425 & 1 & 8 & 11 & 16.800 & -272 \\
\hline 1 & 2 & 26 & 18.000 & 448 & 1 & 3 & 5 & 11.200 & -208 \\
\hline 1 & 5 & 29 & 18.000 & 448 & 1 & 8 & 10 & 11.200 & -200 \\
\hline 1 & 8 & 26 & 13.500 & 378 & 1 & 20 & 23 & 16.800 & -233 \\
\hline 1 & 2 & 14 & 9.000 & 297 & 1 & 15 & 17 & 11.200 & -195 \\
\hline 1 & 1 & 25 & 18.000 & 380 & 1 & 1 & 5 & 22.401 & -259 \\
\hline 1 & 3 & 21 & 13.500 & 330 & 1 & 25 & 29 & 22.400 & -255 \\
\hline 1 & 1 & 19 & 13.500 & 322 & 1 & 2 & 3 & 5.600 & -154 \\
\hline 1 & 10 & 28 & 13.500 & 318 & 1 & 26 & 29 & 16.800 & -215 \\
\hline 1 & 15 & 27 & 9.000 & 267 & 1 & 14 & 16 & 11.199 & -174 \\
\hline 1 & 8 & 14 & 4.500 & 226 & 1 & 13 & 17 & 22.400 & -234 \\
\hline 1 & 9 & 21 & 9.000 & 265 & 1 & 25 & 28 & 16.800 & -199 \\
\hline
\end{tabular}

0 of 100 Single-axis measurements exceed the Axial Allowable Deviation.

The following data are an estimate of the CMM axial point-to-point errors:

$\mathrm{X}$ axis: average point-to-point error is $-11.6 \mathrm{ppm}$.

$Y$ axis: average point-to-point error is $24.5 \mathrm{ppm}$. 
Page 2 of 3

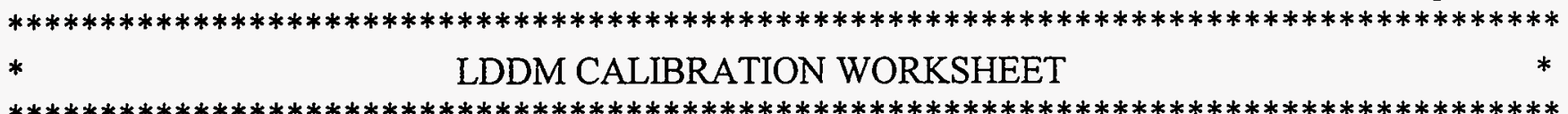

LDDM data taken with ball plate on machine table. Corrected for Angular Errors Only.

Inspected by XXX Department XXX Inspection Date: 01-25-1996

The distances are in inches and deviations in microinches.

Planar Data Performance Specification $=+/-(0.00035$ inch $+25 \mathrm{ppm})$

Inch Groups
Number measured distances

Average absolute deviation

Average deviation

Std dev over work zone

Std dev of multiple runs

Radial bias of standard

Std dev of the standard

Uncertainty of single run

Uncertainty of three runs

Allowable deviation

$\begin{array}{rrrrrr}\frac{\leq 5}{20} & \frac{5-6}{20} & \frac{6-10}{47} & \frac{10-12}{39} & \frac{12-17}{78} & \frac{>17}{96} \\ 122 & 81 & 149 & 167 & 190 & 212 \\ 113 & -59 & 87 & 41 & 52 & 28 \\ 76 & 65 & 152 & 195 & 222 & 254 \\ 86 & 55 & 77 & 74 & 80 & 86 \\ 6 & 6 & 7 & 7 & 8 & 9 \\ 17 & 18 & 21 & 23 & 25 & 29 \\ 323 & 229 & 446 & 530 & 601 & 679 \\ 291 & 211 & 428 & 516 & 587 & 664 \\ 463 & 490 & 575 & 630 & 688 & 800\end{array}$

These data are the 15 most positive and 15 most negative deviations with their ball plate position, sphere pair and nominal distance; respectively ranked as a percentage of the Planar allowable deviation.

\begin{tabular}{|c|c|c|c|c|c|c|c|c|c|}
\hline Position & \multicolumn{2}{|c|}{ Spheres } & Distance & Deviation & Position & \multicolumn{2}{|c|}{ Spheres } & Distance & Deviation \\
\hline 1 & 8 & 19 & 10.600 & 462 & 1 & 16 & 23 & 7.184 & -343 \\
\hline 1 & 2 & 19 & 14.615 & 503 & 1 & 14 & 23 & 17.392 & -439 \\
\hline 1 & 4 & 16 & 9.000 & 392 & 1 & 15 & 23 & 12.070 & -321 \\
\hline 1 & 5 & 28 & 18.851 & 551 & 1 & 14 & 22 & 12.070 & -319 \\
\hline 1 & 4 & 28 & 18.000 & 501 & 1 & 2 & 5 & 16.800 & -362 \\
\hline 1 & 3 & 28 & 18.851 & 513 & 1 & 5 & 8 & 17.392 & -354 \\
\hline 1 & 8 & 25 & 14.615 & 444 & 1 & 13 & 23 & 22.847 & -407 \\
\hline 1 & 9 & 27 & 13.500 & 425 & 1 & 7 & 23 & 24.140 & -407 \\
\hline 1 & 3 & 16 & 10.600 & 379 & 1 & 8 & 23 & 19.059 & -351 \\
\hline 1 & 2 & 25 & 18.851 & 505 & 1 & 13 & 22 & 17.392 & -309 \\
\hline 1 & 3 & 27 & 18.000 & 489 & 1 & 4 & 8 & 12.070 & -248 \\
\hline 1 & 11 & 28 & 14.615 & 435 & 1 & 14 & 21 & 7.184 & -200 \\
\hline 1 & 17 & 28 & 10.600 & 347 & 1 & 8 & 17 & 17.392 & -294 \\
\hline 1 & 2 & 26 & 18.000 & 448 & 1 & 2 & 4 & 11.200 & -236 \\
\hline 1 & 5 & 29 & 18.000 & 448 & 1 & 14 & 17 & 16.800 & -277 \\
\hline
\end{tabular}

0 of 3001 and 2 Axis Measurements exceed the Planar Allowable Deviation.

The following data are an estimate of the CMM planar squareness errors:

The indicated $\mathrm{XY}$ plane squareness is 10.0 (2.06 arcseconds).

* May be affected by yaw, pitch, roll, and straightness of the included axes. 
LDDM data taken with ball plate on machine table. Corrected for Angular Errors Only.

Inspected by XXX Department XXX Inspection Date: 01-25-1996

The distances are in inches and deviations in microinches.

Spatial Data Performance Specification $=+/-(0.00035$ inch $+30 \mathrm{ppm})$

\begin{tabular}{lrrrrrrrr}
$\quad$ Inch Groups & \multicolumn{1}{c}{$\quad$} & $\frac{6-10}{40}$ & $\frac{10-12}{47}$ & $\underline{1214}$ & $\underline{14-17}$ & $\underline{1719}$ & $\underline{1924}$ & $\geq 24$ \\
Number measured distances & 102 & 149 & 167 & 182 & 196 & 255 & 188 & 162 \\
Average absolute deviation & 27 & 87 & 41 & 34 & 66 & 119 & -47 & -19 \\
Average deviation & 112 & 152 & 195 & 220 & 226 & 283 & 215 & 191 \\
Std dev over work zone & 72 & 77 & 74 & 72 & 86 & 79 & 89 & 99 \\
Std dev of multiple runs & 6 & 6 & 7 & 7 & 8 & 8 & 9 & 10 \\
Radial bias of standard & 17 & 19 & 22 & 23 & 25 & 28 & 30 & 34 \\
Std dev of the standard & 326 & 446 & 530 & 584 & 617 & 775 & 592 & 531 \\
Uncertainty of single run & 304 & 428 & 516 & 572 & 600 & 765 & 574 & 505 \\
Uncertainty of three runs & 485 & 566 & 668 & 712 & 782 & 872 & 922 & 1074 \\
Allowable deviation & 485 & & & & & & &
\end{tabular}

These data are the 15 most positive and 15 most negative deviations with their ball plate position, sphere pair and nominal distance; respectively ranked as a percentage of the Spatial allowable deviation.

\begin{tabular}{|c|c|c|c|c|c|c|c|c|c|}
\hline Position & \multicolumn{2}{|c|}{ Spheres } & Distance & Deviation & Position & \multicolumn{2}{|c|}{ Spheres } & Distance & Deviation \\
\hline 1 & 8 & 19 & 10.600 & 462 & 1 & 16 & 23 & 7.184 & -343 \\
\hline 1 & 2 & 19 & 14.615 & 503 & 1 & 14 & 23 & 17.392 & -439 \\
\hline 1 & 4 & 16 & 9.000 & 392 & 1 & 15 & 23 & 12.070 & -321 \\
\hline 1 & 5 & 28 & 18.851 & 551 & 1 & 14 & 22 & 12.070 & -319 \\
\hline 1 & 3 & 16 & 10.600 & 379 & 1 & 2 & 5 & 16.800 & -362 \\
\hline 1 & 8 & 25 & 14.615 & 444 & 1 & 5 & 8 & 17.392 & -354 \\
\hline 1 & 9 & 27 & 13.500 & 425 & 1 & 13 & 23 & 22.847 & -407 \\
\hline 1 & 4 & 28 & 18.000 & 501 & 1 & 8 & 23 & 19.059 & -351 \\
\hline 1 & 3 & 28 & 18.851 & 513 & 1 & 7 & 23 & 24.140 & -407 \\
\hline 1 & 2 & 25 & 18.851 & 505 & 1 & 13 & 22 & 17.392 & -309 \\
\hline 1 & 11 & 28 & 14.615 & 435 & 1 & 14 & 21 & 7.184 & -200 \\
\hline 1 & 3 & 27 & 18.000 & 489 & 1 & 4 & 8 & 12.070 & -248 \\
\hline 1 & 17 & 28 & 10.600 & 347 & 1 & 2 & 4 & 11.200 & -236 \\
\hline 1 & 2 & 26 & 18.000 & 448 & 1 & 8 & 17 & 17.392 & -294 \\
\hline 1 & 5 & 29 & 18.000 & 448 & 1 & 14 & 17 & 16.800 & -277 \\
\hline
\end{tabular}

0 of 300 Total Radial Measurements exceed the Spatial Allowable Deviation. 
LDDM data taken with ball plate 9.5 inches above machine table. Corrected for Angular Errors Only.

$$
16000 \text { Ball plate Exp. date: 08-25-96 }
$$

Software: Name PC1808, ID\# CS-09P-144, Issue A, Revision 06/02/95

Inspected by XXX Department XXX Inspection Date: 01-25-1996

The distances are in inches and deviations in microinches.

Axial Data Performance Specification $=+/-(0.00035$ inch $+17 \mathrm{ppm})$

\begin{tabular}{|c|c|c|c|}
\hline Inch Groups & $<5$ & $5-12$ & $>1$ \\
\hline Number measured distances & $\overline{20}$ & 50 & $\overline{3}$ \\
\hline Average absolute deviation & 40 & 87 & 15 \\
\hline Average deviation & -25 & -83 & -15 \\
\hline Std dev over work zone & 44 & 67 & 8 \\
\hline Std dev of multiple runs & 65 & 60 & 6 \\
\hline Radial bias of standard & 6 & 7 & \\
\hline Std dev of the standard & 17 & 21 & 2 \\
\hline Uncertainty of single run & 162 & 244 & 3 \\
\hline Uncertainty of three runs & 124 & 224 & 0 \\
\hline Allov & 427 & 50 & \\
\hline
\end{tabular}

These data are the 15 most positive and 15 most negative deviations with their ball plate position, sphere pair and nominal distance; respectively ranked as a percentage of the Axial allowable deviation.

\begin{tabular}{|c|c|c|c|c|c|c|c|c|c|}
\hline Position & \multicolumn{2}{|c|}{ Spheres } & Distance & Deviation & Position & Sph & & Distance & Deviation \\
\hline 1 & 17 & 23 & 4.500 & 55 & 1 & 9 & 11 & 11.200 & -273 \\
\hline 1 & 11 & 23 & 9.000 & 41 & 1 & 10 & 11 & 5.599 & -201 \\
\hline 1 & 19 & 20 & 5.600 & 36 & 1 & 2 & 5 & 16.800 & -285 \\
\hline 1 & 3 & 9 & 4.500 & 31 & 1 & 8 & 11 & 16.800 & -282 \\
\hline 1 & 21 & 27 & 4.500 & 30 & 1 & 3 & 5 & 11.200 & -240 \\
\hline 1 & 22 & 28 & 4.500 & 22 & 1 & 7 & 11 & 22.400 & -318 \\
\hline 1 & 13 & 14 & 5.600 & 12 & 1 & 1 & 5 & 22.401 & -316 \\
\hline 1 & 19 & 25 & 4.500 & 9 & 1 & 14 & 17 & 16.800 & -268 \\
\hline 1 & 5 & 23 & 13.500 & 12 & 1 & 15 & 17 & 11.200 & -225 \\
\hline 1 & 13 & 25 & 9.000 & 6 & 1 & 25 & 29 & 22.400 & -275 \\
\hline 1 & 1 & 7 & 4.501 & 1 & 1 & 13 & 17 & 22.400 & -256 \\
\hline 1 & 13 & 19 & 4.500 & -3 & 1 & 20 & 23 & 16.800 & -206 \\
\hline 1 & 19 & 21 & 11.200 & -9 & 1 & 26 & 29 & 16.800 & -205 \\
\hline 1 & 8 & 9 & 5.600 & -9 & 1 & 27 & 29 & 11.200 & -170 \\
\hline 1 & 14 & 20 & 4.500 & -12 & 1 & 9 & 21 & 9.000 & -158 \\
\hline
\end{tabular}

0 of 100 Single-axis measurements exceed the Axial Allowable Deviation.

The following data are an estimate of the CMM axial point-to-point errors:

$\mathrm{X}$ axis: average point-to-point error is $-11.8 \mathrm{ppm}$.

$\mathrm{Y}$ axis: average point-to-point error is $-6.0 \mathrm{ppm}$. 
LDDM data taken with ball plate 9.5 inches above machine table. Corrected for Angular Errors Only. Inspected by XXX Department XXX Inspection Date: 01-25-1996

The distances are in inches and deviations in microinches.

Planar Data Performance Specification $=+/-(0.00035$ inch $+25 \mathrm{ppm})$

\begin{tabular}{|c|c|c|c|c|c|}
\hline Inch Groups & $\leq \underline{5}$ & $\underline{5-6}$ & $\underline{6-10}$ & $10-12$ & $\underline{12-17}$ \\
\hline Number measured distances & 20 & 20 & 47 & 39 & 78 \\
\hline Average absolute deviation & 40 & 72 & 83 & 117 & 140 \\
\hline Average deviation & -25 & -67 & -64 & -105 & -131 \\
\hline Std dev over work zone & 44 & 54 & 80 & 88 & 99 \\
\hline Std dev of multiple runs & 65 & 47 & 64 & 56 & 54 \\
\hline Radial bias of standard & 6 & 6 & 7 & 7 & 8 \\
\hline Std dev of the standard & 17 & 18 & 21 & 23 & 25 \\
\hline Uncertainty of single run & 162 & 198 & 257 & 311 & 357 \\
\hline Uncertainty of three runs & 124 & 183 & 234 & 297 & 346 \\
\hline ole d & 463 & 0 & 75 & 630 & 688 \\
\hline
\end{tabular}

These data are the 15 most positive and 15 most negative deviations with their ball plate position, sphere pair and nominal distance; respectively ranked as a percentage of the Planar allowable deviation.

\begin{tabular}{|c|c|c|c|c|c|c|c|c|c|}
\hline Position & \multicolumn{2}{|c|}{ Spheres } & Distance & Deviation & Position & \multicolumn{2}{|c|}{ Spheres } & Distance & Deviation \\
\hline 1 & 14 & 19 & 7.184 & 173 & 1 & 9 & 23 & 14.368 & -344 \\
\hline 1 & 15 & 19 & 12.070 & 123 & 1 & 9 & 17 & 12.070 & -309 \\
\hline 1 & 8 & 19 & 10.600 & 76 & 1 & 15 & 23 & 12.070 & -303 \\
\hline 1 & 9 & 19 & 14.368 & 85 & 1 & 9 & 29 & 17.541 & -361 \\
\hline 1 & 17 & 23 & 4.500 & 55 & 1 & 10 & 17 & 7.183 & -239 \\
\hline 1 & 14 & 25 & 10.600 & 72 & 1 & 5 & 9 & 12.070 & -285 \\
\hline 1 & 2 & 9 & 7.184 & 53 & 1 & 9 & 11 & 11.200 & -273 \\
\hline 1 & 10 & 19 & 19.059 & 68 & 1 & 5 & 8 & 17.392 & -337 \\
\hline 1 & 17 & 22 & 7.184 & 40 & 1 & 14 & 23 & 17.392 & -335 \\
\hline 1 & 19 & 20 & 5.600 & 36 & 1 & 7 & 23 & 24.140 & -404 \\
\hline 1 & 11 & 23 & 9.000 & 41 & 1 & 15 & 29 & 14.368 & -300 \\
\hline 1 & 3 & 10 & 7.184 & 37 & 1 & 8 & 23 & 19.059 & -342 \\
\hline 1 & 17 & 28 & 10.600 & 43 & 1 & 10 & 11 & 5.599 & -201 \\
\hline 1 & 1 & 9 & 12.071 & 44 & 1 & 7 & 29 & 26.154 & -409 \\
\hline 1 & 3 & 9 & 4.500 & 31 & 1 & 5 & 7 & 22.848 & -373 \\
\hline
\end{tabular}

0 of 3001 and 2 Axis Measurements exceed the Planar Allowable Deviation. The following data are an estimate of the CMM planar squareness errors: The indicated XY plane squareness is 6.1 (1.26 arcseconds).

* May be affected by yaw, pitch, roll, and straightness of the included axes. 
Page 3 of 3

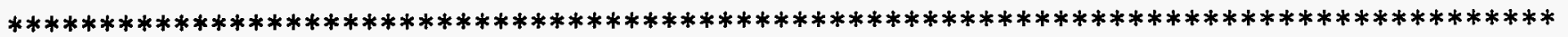

*

LDDM CALIBRATION WORKSHEET

*

$* * * * * * * * * * * * * * * * * * * * * * * * * * * * * * * * * * * * * * * * * * * * * * * * * * * * * * * * * * * * * * * * * * * * * * * * * * * * * * * * * * *$

LDDM data taken with ball plate 9.5 inches above machine table. Corrected for Angular Errors Only. Inspected by XXX Department XXX Inspection Date: 01-25-1996

The distances are in inches and deviations in microinches.

Spatial Data $\quad$ Performance Specification $=+/-(0.00035$ inch $+30 \mathrm{ppm})$

\begin{tabular}{|c|c|c|c|c|c|c|c|c|}
\hline Inch Groups & $\leq 6$ & $\underline{6-10}$ & $\underline{10-12}$ & $\underline{1214}$ & $14-17$ & $\underline{1719}$ & $\underline{1924}$ & $\geq 2$ \\
\hline Number measured distances & 40 & 47 & 39 & 34 & 44 & 41 & 39 & \\
\hline Average absolute deviation & 56 & 83 & 117 & 127 & 150 & 158 & 217 & \\
\hline Average deviation & -46 & -64 & -105 & -115 & -144 & -156 & -213 & \\
\hline Std dev over work zone & 53 & 80 & 88 & 99 & 98 & 97 & 103 & \\
\hline td dev of multiple runs & 57 & 64 & 56 & 56 & 52 & 58 & 55 & \\
\hline Radial bias of standard & 6 & 6 & 7 & 7 & 8 & 8 & 9 & \\
\hline Std dev of the standard & 17 & 19 & 22 & 23 & 25 & 28 & 30 & \\
\hline Uncertainty of single run & 182 & 256 & 311 & 338 & 371 & 387 & 492 & \\
\hline ncertainty of three runs & 157 & 234 & 297 & 325 & 361 & 375 & 483 & \\
\hline Alowable deviation & 485 & 6 & 668 & 712 & 782 & 872 & $922+2$ & \\
\hline
\end{tabular}

These data are the 15 most positive and 15 most negative deviations with their ball plate position, sphere pair and nominal distance; respectively ranked as a percentage of the Spatial allowable deviation.

\begin{tabular}{|c|c|c|c|c|c|c|c|c|c|}
\hline Position & \multicolumn{2}{|c|}{ Spheres } & Distance & Deviation & $\underline{\text { Position }}$ & \multicolumn{2}{|c|}{ Spheres } & Distance & Deviation \\
\hline 1 & 14 & 19 & 7.184 & 173 & 1 & 9 & 23 & 14.368 & -344 \\
\hline 1 & 15 & 19 & 12.070 & 123 & 1 & 9 & 17 & 12.070 & -309 \\
\hline 1 & 17 & 23 & 4.500 & 55 & 1 & 15 & 23 & 12.070 & -303 \\
\hline 1 & 8 & 19 & 10.600 & 76 & 1 & 10 & 17 & 7.183 & -239 \\
\hline 1 & 9 & 19 & 14.368 & 85 & 1 & 9 & 29 & 17.541 & -361 \\
\hline 1 & 14 & 25 & 10.600 & 72 & 1 & 5 & 9 & 12.070 & -285 \\
\hline 1 & 2 & 9 & 7.184 & 53 & 1 & 9 & 11 & 11.200 & -273 \\
\hline 1 & 10 & 19 & 19.059 & 68 & 1 & 10 & 11 & 5.599 & -201 \\
\hline 1 & 17 & 22 & 7.184 & 40 & 1 & 5 & 8 & 17.392 & -337 \\
\hline 1 & 19 & 20 & 5.600 & 36 & 1 & 14 & 23 & 17.392 & -335 \\
\hline 1 & 11 & 23 & 9.000 & 41 & 1 & 15 & 29 & 14.368 & -300 \\
\hline 1 & 3 & 10 & 7.184 & 37 & 1 & 7 & 23 & 24.140 & -404 \\
\hline 1 & 17 & 28 & 10.600 & 43 & 1 & 8 & 23 & 19.059 & -342 \\
\hline 1 & 3 & 9 & 4.500 & 31 & 1 & 16 & 23 & 7.184 & -205 \\
\hline 1 & 21 & 27 & 4.500 & 30 & 1 & 7 & 29 & 26.154 & -409 \\
\hline
\end{tabular}

0 of 300 Total Radial Measurements exceed the Spatial Allowable Deviation. 
Page 1 of 3

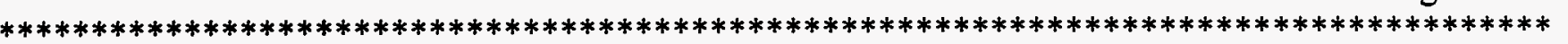

LDDM data taken with both positions analyzed. Corrected for Angular Errors Only.

$$
16000 \text { Ball plate Exp. date: 08-25-96 }
$$

Software: Name PC1808, ID\# CS-09P-144, Issue A, Revision 06/02/95

Inspected by XXX Department XXX Inspection Date: 01-25-1996

The distances are in inches and deviations in microinches.

Axial Data Performance Specification $=+/-(0.00035$ inch $+17 \mathrm{ppm})$

\begin{tabular}{lrrr}
\multicolumn{1}{c}{ Inch Groups } & $\leq 5$ & $5-12$ & $\geq 12$ \\
Number measured distances & 40 & 100 & 60 \\
Average absolute deviation & 81 & 113 & 224 \\
Average deviation & 44 & -42 & -41 \\
Std dev over work zone & 93 & 129 & 251 \\
Std dev of multiple runs & 76 & 66 & 67 \\
Radial bias of standard & 6 & 7 & 8 \\
Std dev of the standard & 17 & 21 & 25 \\
Uncertainty of single run & 279 & 362 & 683 \\
Uncertainty of three runs & 250 & 346 & 675 \\
Allowable deviation & 427 & 503 & 580
\end{tabular}

$\gg \gg \gg>* * * *$ CMM Uncertainty Exceeds the Axial Allowable Deviation $* * * * *<<<<<$

These data are the 15 most positive and 15 most negative deviations with their ball plate position, sphere pair and nominal distance; respectively ranked as a percentage of the Axial allowable deviation.

\begin{tabular}{|c|c|c|c|c|c|c|c|c|c|}
\hline Position & \multicolumn{2}{|c|}{ Spheres } & Distance & Deviation & Position & \multicolumn{2}{|c|}{ Spheres } & Distance & Deviation \\
\hline 1 & 4 & 16 & 9.000 & 392 & 1 & 2 & 5 & 16.800 & -362 \\
\hline 1 & 4 & 28 & 18.000 & 501 & 2 & 9 & 11 & 11.200 & -273 \\
\hline 1 & 3 & 27 & 18.000 & 489 & 2 & 10 & 11 & 5.599 & -201 \\
\hline 1 & 9 & 27 & 13.500 & 425 & 2 & 2 & 5 & 16.800 & -285 \\
\hline 1 & 2 & 26 & 18.000 & 448 & 2 & 8 & 11 & 16.800 & -282 \\
\hline 1 & 5 & 29 & 18.000 & 448 & 2 & 3 & 5 & 11.200 & -240 \\
\hline 1 & 8 & 26 & 13.500 & 378 & 1 & 2 & 4 & 11.200 & -236 \\
\hline 1 & 2 & 14 & 9.000 & 297 & 1 & 14 & 17 & 16.800 & -277 \\
\hline 1 & 1 & 25 & 18.000 & 380 & 2 & 7 & 11 & 22.400 & -318 \\
\hline 1 & 3 & 21 & 13.500 & 330 & 2 & 1 & 5 & 22.401 & -316 \\
\hline 1 & 1 & 19 & 13.500 & 322 & 1 & 8 & 11 & 16.800 & -272 \\
\hline 1 & 10 & 28 & 13.500 & 318 & 2 & 14 & 17 & 16.800 & -268 \\
\hline 1 & 15 & 27 & 9.000 & 267 & 2 & 15 & 17 & 11.200 & -225 \\
\hline 1 & 8 & 14 & 4.500 & 226 & 1 & 3 & 5 & 11.200 & -208 \\
\hline 1 & 9 & 21 & 9.000 & 265 & 2 & 25 & 29 & 22.400 & -275 \\
\hline
\end{tabular}

0 of 200 Single-axis measurements exceed the Axial Allowable Deviation.

The following data are an estimate of the CMM axial point-to-point errors:

$\mathrm{X}$ axis: average point-to-point error is $-11.7 \mathrm{ppm}$.

$\mathrm{Y}$ axis: average point-to-point error is $9.2 \mathrm{ppm}$. 
LDDM data taken with both position analyzed. Corrected for Angular Errors Only.

Inspected by XXX Department XXX Inspection Date: 01-25-1996

The distances are in inches and deviations in microinches.

Planar Data Performance Specification $=+/-(0.00035$ inch $+25 \mathrm{ppm})$

\begin{tabular}{|c|c|c|c|c|c|}
\hline Inch Groups & $\leq 5$ & $\underline{5-6}$ & $\underline{6-10}$ & $\underline{10-12}$ & $\underline{12-17}$ \\
\hline Number measured distances & 40 & 40 & 94 & 78 & 156 \\
\hline Average absolute deviation & 81 & 76 & 116 & 142 & 165 \\
\hline Average deviation & 44 & -63 & 11 & -32 & -40 \\
\hline Std dev over work zone & 93 & 59 & 143 & 168 & 195 \\
\hline Std dev of multiple runs & 76 & 51 & 71 & 66 & 68 \\
\hline Radial bias of standard & 6 & 6 & 7 & 7 & 8 \\
\hline Std dev of the standard & 17 & 18 & 21 & 23 & 25 \\
\hline Uncertainty of single run & 279 & 213 & 388 & 455 & 524 \\
\hline Uncertainty of three runs & 250 & 196 & 370 & 442 & 512 \\
\hline llowable deviation & 463 & 0 & 575 & 0 & 688 \\
\hline
\end{tabular}

These data are the 15 most positive and 15 most negative deviations with their ball plate position, sphere pair and nominal distance; respectively ranked as a percentage of the Planar allowable deviation.

\begin{tabular}{|c|c|c|c|c|c|c|c|c|c|}
\hline Position & \multicolumn{2}{|c|}{ Spheres } & Distance & Deviation & Position & \multicolumn{2}{|c|}{ Spheres } & Distance & Deviation \\
\hline 1 & 8 & 19 & 10.600 & 462 & 1 & 16 & 23 & 7.184 & -343 \\
\hline 1 & 2 & 19 & 14.615 & 503 & 1 & 14 & 23 & 17.392 & -439 \\
\hline 1 & 4 & 16 & 9.000 & 392 & 1 & 15 & 23 & 12.070 & -321 \\
\hline 1 & 5 & 28 & 18.851 & 551 & 1 & 14 & 22 & 12.070 & -319 \\
\hline 1 & 4 & 28 & 18.000 & 501 & 2 & 9 & 23 & 14.368 & -344 \\
\hline 1 & 3 & 28 & 18.851 & 513 & 2 & 9 & 17 & 12.070 & -309 \\
\hline 1 & 8 & 25 & 14.615 & 444 & 1 & 2 & 5 & 16.800 & -362 \\
\hline 1 & 9 & 27 & 13.500 & 425 & 2 & 15 & 23 & 12.070 & -303 \\
\hline 1 & 3 & 16 & 10.600 & 379 & 2 & 9 & 29 & 17.541 & -361 \\
\hline 1 & 2 & 25 & 18.851 & 505 & 2 & 10 & 17 & 7.183 & -239 \\
\hline 1 & 3 & 27 & 18.000 & 489 & 1 & 5 & 8 & 17.392 & -354 \\
\hline 1 & 11 & 28 & 14.615 & 435 & 1 & 13 & 23 & 22.847 & -407 \\
\hline 1 & 17 & 28 & 10.600 & 347 & 2 & 5 & 9 & 12.070 & -285 \\
\hline 1 & 2 & 26 & 18.000 & 448 & 2 & 9 & 11 & 11.200 & -273 \\
\hline 1 & 5 & 29 & 18.000 & 448 & 2 & 5 & 8 & 17.392 & -337 \\
\hline
\end{tabular}

0 of 6001 and 2 Axis Measurements exceed the Planar Allowable Deviation.

The following data are an estimate of the CMM planar squareness errors:

The indicated $\mathrm{XY}$ plane squareness is 8.1 (1.66 arcseconds).

* May be affected by yaw, pitch, roll, and straightness of the included axes. 
LDDM data taken with both positions analyzed. Corrected for Angular Errors Only. Inspected by XXX Department XXX Inspection Date: 01-25-1996

The distances are in inches and deviations in microinches.

Spatial Data $\quad$ Performance Specification $=+/-(0.00035$ inch $+30 \mathrm{ppm})$

$\begin{array}{lrrrrrrrr}\quad \text { Inch Groups } & \frac{\leq 6}{80} & \frac{6-10}{94} & \frac{10-12}{78} & \frac{1214}{68} & \frac{14-17}{88} & \frac{1719}{82} & \frac{1924}{78} & \frac{>24}{32} \\ \text { Number measured distances } & 79 & 116 & 142 & 154 & 173 & 206 & 202 & 206 \\ \text { Average absolute deviation } & -9 & 11 & -32 & -41 & -39 & -19 & -130 & -134 \\ \text { Average deviation } & 94 & 143 & 168 & 185 & 203 & 252 & 187 & 190 \\ \text { Std dev over work zone } & 65 & 71 & 66 & 65 & 71 & 69 & 74 & 84 \\ \text { Std dev of multiple runs } & 6 & 6 & 7 & 7 & 8 & 8 & 9 & 10 \\ \text { Radial bias of standard } & 17 & 19 & 22 & 23 & 25 & 28 & 30 & 34 \\ \text { Std dev of the standard } & 270 & 388 & 455 & 496 & 548 & 663 & 567 & 581 \\ \text { Uncertainty of single run } & 248 & 370 & 442 & 484 & 535 & 654 & 554 & 565 \\ \text { Uncertainty of three runs } & 485 & 566 & 668 & 712 & 782 & 872 & 922 & 1074 \\ \text { Allowable deviation } & & & & & & & \end{array}$

These data are the 15 most positive and 15 most negative deviations with their ball plate position, sphere pair and nominal distance; respectively ranked as a percentage of the Spatial allowable deviation.

\begin{tabular}{|c|c|c|c|c|c|c|c|c|c|}
\hline Position & \multicolumn{2}{|c|}{ Spheres } & Distance & Deviation & Position & \multicolumn{2}{|c|}{ Spheres } & Distance & Deviation \\
\hline 1 & 8 & 19 & 10.600 & 462 & 1 & 16 & 23 & 7.184 & -343 \\
\hline 1 & 2 & 19 & 14.615 & 503 & 1 & 14 & 23 & 17.392 & -439 \\
\hline 1 & 4 & 16 & 9.000 & 392 & 1 & 15 & 23 & 12.070 & -321 \\
\hline 1 & 5 & 28 . & 18.851 & 551 & 1 & 14 & 22 & 12.070 & -319 \\
\hline 1 & 3 & 16 & 10.600 & 379 & 2 & 9 & 23 & 14.368 & -344 \\
\hline 1 & 8 & 25 & 14.615 & 444 & 2 & 9 & 17 & 12.070 & -309 \\
\hline 1 & 9 & 27 & 13.500 & 425 & 2 & 15 & 23 & 12.070 & -303 \\
\hline 1 & 4 & 28 & 18.000 & 501 & 1 & 2 & 5 & 16.800 & -362 \\
\hline 1 & 3 & 28 & 18.851 & 513 & 2 & 10 & 17 & 7.183 & -239 \\
\hline 1 & 2 & 25 & 18.851 & 505 & 2 & 9 & 29 & 17.541 & -361 \\
\hline 1 & 11 & 28 & 14.615 & 435 & 1 & 5 & 8 & 17.392 & -354 \\
\hline 1 & 3 & 27 & 18.000 & 489 & 2 & 5 & 9 & 12.070 & -285 \\
\hline 1 & 17 & 28 & 10.600 & 347 & 2 & 9 & 11 & 11.200 & -273 \\
\hline 1 & 2 & 26 & 18.000 & 448 & 1 & 13 & 23 & 22.847 & -407 \\
\hline 1 & 5 & 29 & 18.000 & 448 & 2 & 10 & 11 & 5.599 & -201 \\
\hline
\end{tabular}

0 of 600 Total Radial Measurements exceed the Spatial Allowable Deviation. 
Page 1 of 3

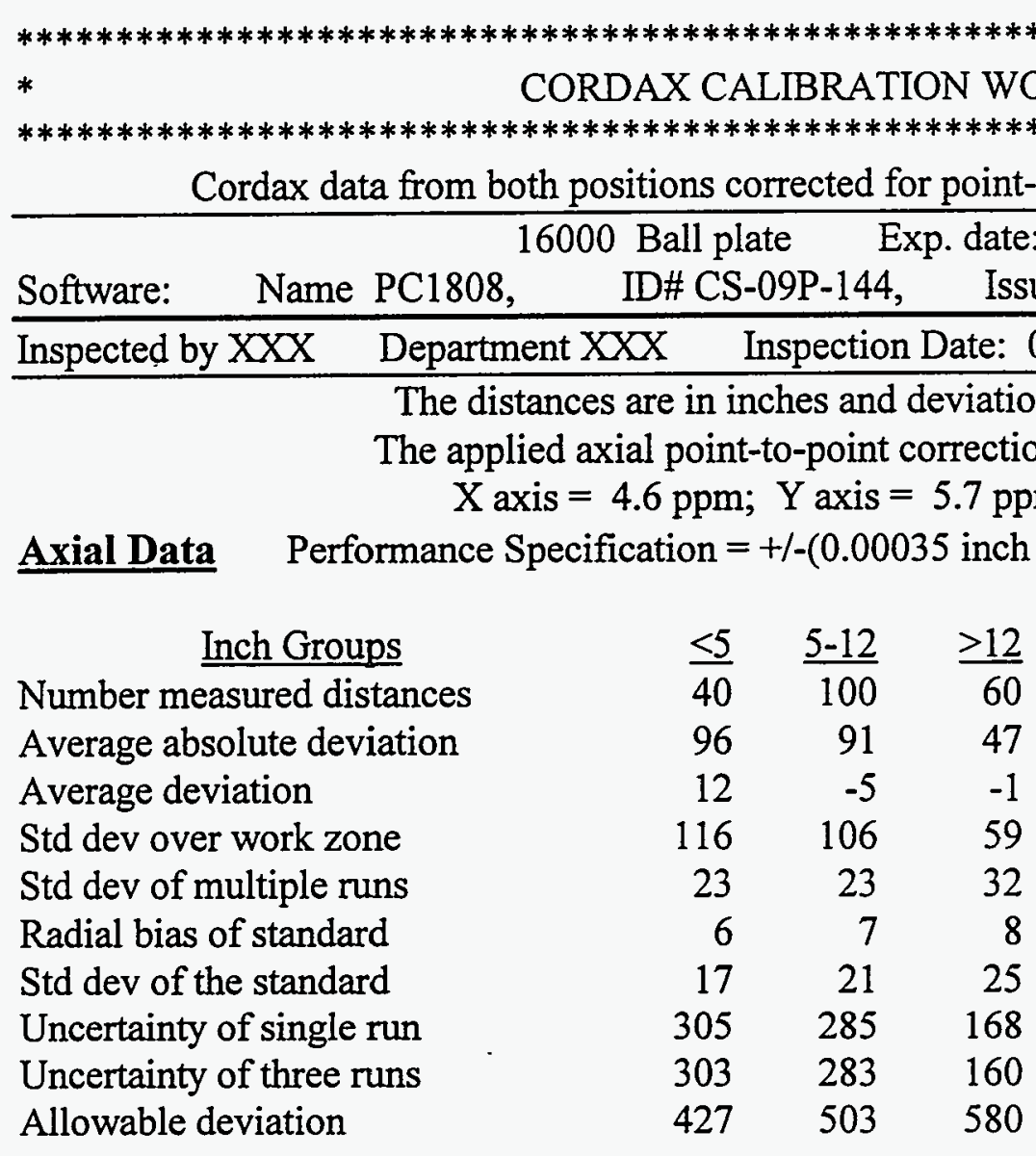

These data are the 15 most positive and 15 most negative deviations with their ball plate position, sphere pair and nominal distance; respectively ranked as a percentage of the Axial allowable deviation.

\begin{tabular}{|c|c|c|c|c|c|c|c|c|c|}
\hline Position & \multicolumn{2}{|c|}{ Spheres } & Distance & Deviation & Position & \multicolumn{2}{|c|}{ Spheres } & Distance & Deviation \\
\hline 2 & 4 & 16 & 9.000 & 254 & 2 & 13 & 19 & 4.500 & -192 \\
\hline 2 & 5 & 17 & 9.000 & 245 & 1 & 13 & 19 & 4.500 & -192 \\
\hline 2 & 1 & 13 & 9.000 & 216 & 1 & 15 & 21 & 4.500 & -181 \\
\hline 2 & 3 & 15 & 9.000 & 212 & 1 & 14 & 20 & 4.500 & -180 \\
\hline 2 & 4 & 10 & 4.500 & 170 & 2 & 13 & 25 & 9.000 & -190 \\
\hline 2 & 3 & 9 & 4.500 & 166 & 1 & 16 & 22 & 4.500 & -154 \\
\hline 2 & 5 & 11 & 4.500 & 164 & 1 & 17 & 23 & 4.500 & -153 \\
\hline 2 & 2 & 14 & 9.000 & 192 & 2 & 16 & 28 & 9.000 & -179 \\
\hline 2 & 2 & 8 & 4.500 & 155 & 2 & 17 & 29 & 9.000 & -178 \\
\hline 1 & 3 & 9 & 4.500 & 155 & 1 & 9 & 21 & 9.000 & -172 \\
\hline 1 & 5 & 11 & 4.500 & 149 & 2 & 16 & 22 & 4.500 & -143 \\
\hline 1 & 4 & 10 & 4.500 & 142 & 2 & 15 & 21 & 4.500 & -141 \\
\hline 1 & 1 & 13 & 9.000 & 167 & 2 & 17 & 23 & 4.500 & -140 \\
\hline 1 & 5 & 17 & 9.000 & 165 & 1 & 8 & 20 & 9.000 & -163 \\
\hline 1 & 3 & 15 & 9.000 & 164 & 2 & 15 & 27 & 9.000 & -152 \\
\hline
\end{tabular}

0 of 200 Single-axis measurements exceed the Axial Allowable Deviation.

The following data are an estimate of the CMM axial point-to-point errors:

$\mathrm{X}$ axis: average point-to-point error is $0.0 \mathrm{ppm}$.

$\mathrm{Y}$ axis: average point-to-point error is $-0.0 \mathrm{ppm}$. 
Cordax data from both positions corrected for point-to-point and squareness errors.

Inspected by XXX Department XXX Inspection Date: 01-25-1996

The distances are in inches and deviations in microinches.

The applied planar squareness corrections were as follows:

$\mathrm{XY}$ plane $=-7.0 \mathrm{ppm} ; \mathrm{XZ}$ plane $=0 \mathrm{ppm} ; \mathrm{YZ}$ plane $=0 \mathrm{ppm}$

Planar Data Performance Specification $=+/-(0.00035$ inch $+25 \mathrm{ppm})$

\begin{tabular}{|c|c|c|c|c|c|c|}
\hline Inch Groups & $\leq 5$ & $\underline{5-6}$ & $\underline{6-10}$ & $10-12$ & $\underline{12-17}$ & $\geq 17$ \\
\hline Number measured distances & 40 & 40 & 94 & 78 & 156 & 192 \\
\hline Average absolute deviation & 96 & 59 & 113 & 113 & 91 & 79 \\
\hline Average deviation & 12 & -7 & -6 & -9 & -3 & 7 \\
\hline Std dev over work zone & 116 & 67 & 141 & 140 & 121 & 100 \\
\hline Std dev of multiple runs & 23 & 18 & 26 & 26 & 32 & 35 \\
\hline Radial bias of standard & 6 & 6 & 7 & 7 & 8 & 9 \\
\hline Std dev of the standard & 17 & 18 & 21 & 23 & 25 & 29 \\
\hline Uncertainty of single run & 305 & 185 & 368 & 365 & 311 & 268 \\
\hline Uncertainty of three runs & 303 & 183 & 365 & 362 & 307 & 262 \\
\hline Allowable deviation & 463 & 490 & 575 & 630 & 688 & 800 \\
\hline
\end{tabular}

These data are the 15 most positive and 15 most negative deviations with their ball plate position, sphere pair and nominal distance; respectively ranked as a percentage of the Planar allowable deviation.

\begin{tabular}{|c|c|c|c|c|c|c|c|c|c|}
\hline Position & \multicolumn{2}{|c|}{ Spheres } & Distance & Deviation & Position & \multicolumn{2}{|c|}{ Spheres } & Distance & Deviation \\
\hline 2 & 3 & 10 & 7.184 & 334 & 2 & 13 & 20 & 7.184 & -373 \\
\hline 2 & 3 & 16 & 10.600 & 387 & 1 & 13 & 20 & 7.184 & -296 \\
\hline 1 & 3 & 10 & 7.184 & 321 & 2 & 13 & 21 & 12.070 & -352 \\
\hline 2 & 2 & 16 & 14.368 & 344 & 2 & 16 & 23 & 7.184 & -285 \\
\hline 1 & 3 & 16 & 10.600 & 288 & 2 & 7 & 20 & 10.600 & -325 \\
\hline 2 & 21 & 28 & 7.184 & 247 & 2 & 13 & 26 & 10.600 & -316 \\
\hline 1 & 2 & .10 & 12.071 & 297 & 2 & 7 & 21 & 14.368 & -354 \\
\hline 2 & 4 & 16 & 9.000 & 254 & 1 & 7 & 20 & 10.600 & -291 \\
\hline 2 & 2 & 10 & 12.071 & 280 & 2 & 14 & 21 & 7.184 & -233 \\
\hline 2 & 5 & 17 & 9.000 & 245 & 1 & 16 & 23 & 7.184 & -227 \\
\hline 1 & 2 & 16 & 14.368 & 282 & 2 & 16 & 29 & 10.600 & -256 \\
\hline 1 & 21 & 28 & 7.184 & 206 & 2 & 13 & 19 & 4.500 & -192 \\
\hline 2 & 2 & 13 & 10.600 & 235 & 1 & 13 & 19 & 4.500 & -192 \\
\hline 2 & 1 & 13 & 9.000 & 216 & 1 & 7 & 21 & 14.368 & -293 \\
\hline 1 & 2 & 9 & 7.184 & 197 & 1 & 14 & 21 & 7.184 & -217 \\
\hline
\end{tabular}

0 of 6001 and 2 Axis Measurements exceed the Planar Allowable Deviation. The following data are an estimate of the CMM planar squareness errors:

The indicated XY plane squareness is 0.0 ( 0.01 arcseconds).

* May be affected by yaw, pitch, roll, and straightness of the included axes. 
Cordax data from both positions corrected for point-to-point and squareness errors.

Inspected by XXX Department XXX Inspection Date: 01-25-1996

The distances are in inches and deviations in microinches.

Spatial Data $\quad$ Performance Specification $=+/-(0.00035$ inch $+30 \mathrm{ppm})$

$\begin{array}{lrrrrrrrr}\quad \text { Inch Groups } & \leq 6 & \frac{6-10}{10} & \underline{10-12} & \underline{1214} & \underline{14-17} & \underline{1719} & \underline{1924} & \frac{24}{32} \\ \text { Number measured distances } & 80 & 94 & 78 & 68 & 88 & 82 & 78 & 32 \\ \text { Average absolute deviation } & 78 & 113 & 113 & 98 & 85 & 82 & 77 & 80 \\ \text { Average deviation } & 2 & -6 & -9 & 4 & -9 & 20 & 1 & -13 \\ \text { Std dev over work zone } & 94 & 141 & 140 & 124 & 119 & 99 & 99 & 102 \\ \text { Std dev of multiple runs } & 21 & 26 & 26 & 30 & 33 & 33 & 34 & 39 \\ \text { Radial bias of standard } & 6 & 6 & 7 & 7 & 8 & 8 & 9 & 10 \\ \text { Std dev of the standard } & 17 & 19 & 22 & 23 & 25 & 28 & 30 & 34 \\ \text { Uncertainty of single run } & 249 & 367 & 365 & 324 & 302 & 269 & 263 & 276 \\ \text { Uncertainty of three runs } & 247 & 365 & 362 & 320 & 297 & 264 & 257 & 269 \\ \text { Allowable deviation } & 485 & 566 & 668 & 712 & 782 & 872 & 922 & 1074\end{array}$

These data are the 15 most positive and 15 most negative deviations with their ball plate position, sphere pair and nominal distance; respectively ranked as a percentage of the Spatial allowable deviation.

\begin{tabular}{|c|c|c|c|c|c|c|c|c|c|}
\hline Position & \multicolumn{2}{|c|}{ Spheres } & Distance & Deviation & Position & \multicolumn{2}{|c|}{ Spheres } & Distance & Deviation \\
\hline 2 & 3 & 10 & 7.184 & 334 & 2 & $\overline{13}$ & 20 & 7.184 & -373 \\
\hline 2 & 3 & 16 & 10.600 & 387 & 1 & 13 & 20 & 7.184 & -296 \\
\hline 1 & 3 & 10 & 7.184 & 321 & 2 & 16 & 23 & 7.184 & -285 \\
\hline 2 & 2 & 16 & 14.368 & 344 & 2 & 13 & 21 & 12.070 & -352 \\
\hline 2 & 21 & 28 & 7.184 & 247 & 2 & 7 & 20 & 10.600 & -325 \\
\hline 1 & 3 & 16 & 10.600 & 288 & 2 & 13 & 26 & 10.600 & -316 \\
\hline 1 & 2 & 10 & 12.071 & 297 & 2 & 7 & 21 & 14.368 & -354 \\
\hline 2 & 4 & 16 & 9.000 & 254 & 1 & 7 & 20 & 10.600 & -291 \\
\hline 2 & 5 & 17 & 9.000 & 245 & 2 & 14 & 21 & 7.184 & -233 \\
\hline 2 & 2 & 10 & 12.071 & 280 & 1 & 16 & 23 & 7.184 & -227 \\
\hline 1 & 21 & 28 & 7.184 & 206 & 2 & 13 & 19 & 4.500 & -192 \\
\hline 1 & 2 & 16 & 14.368 & 282 & 1 & 13 & 19 & 4.500 & -192 \\
\hline 2 & 2 & 13 & 10.600 & 235 & 2 & 16 & 29 & 10.600 & -256 \\
\hline 2 & 4 & 10 & 4.500 & 170 & 1 & 14 & 21 & 7.184 & -217 \\
\hline 2 & 1 & 13 & 9.000 & 216 & 1 & 7 & 21 & 14.368 & -293 \\
\hline
\end{tabular}

0 of 600 Total Radial Measurements exceed the Spatial Allowable Deviation. 
LDDM Data Corrected for point-to-point and squareness errors. Both positions used for the analysis.

Software: Name PC1808, ID\# CS-09P-144, Issue A, Revision 06/02/95

Inspected by XXX Department XXX Inspection Date: 01-25-1996

The distances are in inches and deviations in microinches.

The applied axial point-to-point corrections were as follows:

$\mathrm{X}$ axis $=7.5 \mathrm{ppm} ; \mathrm{Y}$ axis $=52.7 \mathrm{ppm} ; \mathrm{Z}$-axis $=0$

Axial Data Performance Specification $=+/-(0.00035$ inch $+17 \mathrm{ppm})$

Inch Groups

Number measured distances

Average absolute deviation

Average deviation

Std dev over work zone

Std dev of multiple runs

Radial bias of standard

Std dev of the standard

Uncertainty of single run

Uncertainty of three runs

Allowable deviation

$\begin{array}{rrr}\frac{55}{40} & \frac{5-12}{100} & \frac{>12}{60} \\ 55 & 42 & 33 \\ 8 & -5 & -3 \\ 68 & 54 & 41 \\ 41 & 33 & 38 \\ 6 & 7 & 8 \\ 17 & 21 & 25 \\ 191 & 154 & 133 \\ 179 & 144 & 117 \\ 427 & 503 & 580\end{array}$

These data are the 15 most positive and 15 most negative deviations with their ball plate position, sphere pair and nominal distance; respectively ranked as a percentage of the Axial allowable deviation.

\begin{tabular}{|c|c|c|c|c|c|c|c|c|c|}
\hline Position & $\underline{\mathrm{Sph}}$ & & Distance & Deviation & Position & \multicolumn{2}{|c|}{ Spheres } & Distance & Deviation \\
\hline 1 & 4 & 10 & 4.500 & 179 & 1 & 13 & 19 & 4.500 & -136 \\
\hline 1 & 4 & 16 & 9.000 & 203 & 2 & 15 & 21 & 4.500 & -116 \\
\hline 1 & 5 & 11 & 4.500 & 147 & 1 & 7 & 19 & 9.000 & -119 \\
\hline 1 & 5 & 17 & 9.000 & 122 & 1 & 16 & 28 & 9.000 & -118 \\
\hline 1 & 2 & 14 & 9.000 & 112 & 1 & 16 & 22 & 4.500 & -99 \\
\hline 1 & 1 & 2 & 5.601 & 99 & 1 & 14 & 20 & 4.500 & -98 \\
\hline 2 & 3 & 15 & 9.000 & 93 & 2 & 13 & 19 & 4.500 & -97 \\
\hline 1 & 4 & 22 & 13.500 & 104 & 2 & 8 & 20 & 9.000 & -113 \\
\hline 2 & 3 & 9 & 4.500 & 74 & 2 & 9 & 21 & 9.000 & -97 \\
\hline 1 & 2 & 8 & 4.500 & 71 & 1 & 11 & 23 & 9.000 & -93 \\
\hline 1 & 1 & 13 & 9.000 & 82 & 2 & 7 & 19 & 9.000 & -91 \\
\hline 2 & 21 & 27 & 4.500 & 66 & 1 & 14 & 26 & 9.000 & -88 \\
\hline 1 & 1 & 7 & 4.501 & 65 & 2 & 14 & 20 & 4.500 & -74 \\
\hline 2 & 13 & 15 & 11.200 & 82 & 2 & 16 & 22 & 4.500 & -73 \\
\hline 1 & 19 & 25 & 4.500 & 64 & 1 & 10 & 28 & 13.500 & -94 \\
\hline
\end{tabular}

0 of 200 Single-axis measurements exceed the Axial Allowable Deviation.

The following data are an estimate of the CMM axial point-to-point errors:

$\mathrm{X}$ axis: average point-to-point error is $0.0 \mathrm{ppm}$.

$\mathrm{Y}$ axis: average point-to-point error is $0.0 \mathrm{ppm}$. 
LDDM Data Corrected for point-to-point and squareness errors. Both positions used for the analysis.

Inspected by XXX

Department XXX Inspection Date: 01-25-1996

The distances are in inches and deviations in microinches.

The applied planar squareness corrections were as follows:

$\mathrm{XY}$ plane $=6.3 \mathrm{ppm} ; \mathrm{XZ}$ plane $=0 \mathrm{ppm} ; \mathrm{YZ}$ plane $=0 \mathrm{ppm}$

Planar Data Performance Specification $=+/-(0.00035$ inch $+25 \mathrm{ppm})$

\begin{tabular}{|c|c|c|c|c|c|c|}
\hline Inch Groups & $\leq 5$ & $\underline{5-6}$ & $6-10$ & $\underline{10-12}$ & $12-17$ & $\geq 17$ \\
\hline Number measured distances & 40 & 40 & 94 & 78 & 156 & 192 \\
\hline Average absolute deviation & 55 & 25 & 85 & 71 & 75 & 69 \\
\hline Average deviation & 8 & 1 & -0 & -8 & -10 & 2 \\
\hline Std dev over work zone & 68 & 32 & 101 & 93 & 94 & 85 \\
\hline Std dev of multiple runs & 41 & 25 & 38 & 38 & 38 & 39 \\
\hline Radial bias of standard & 6 & 6 & 7 & 7 & 8 & 0 \\
\hline Std dev of the standard & 17 & 18 & 21 & 23 & 25 & 29 \\
\hline Uncertainty of single run & 191 & 99 & 275 & 247 & 253 & 236 \\
\hline Uncertainty of three runs & 179 & 90 & 268 & 239 & 245 & 227 \\
\hline Allowable deviation & 463 & 490 & 575 & 630 & 688 & 800 \\
\hline
\end{tabular}

These data are the 15 most positive and 15 most negative deviations with their ball plate position, sphere pair and nominal distance; respectively ranked as a percentage of the Planar allowable deviation.

\begin{tabular}{|c|c|c|c|c|c|c|c|c|c|}
\hline Position & \multicolumn{2}{|c|}{ Spheres } & Distance & Deviation & Position & \multicolumn{2}{|c|}{ Spheres } & Distance & Deviation \\
\hline 1 & 4 & 10 & 4.500 & 179 & 1 & 16 & 23 & 7.184 & -252 \\
\hline 1 & 3 & 10 & 7.184 & 204 & 1 & 13 & 20 & 7.184 & -233 \\
\hline 1 & 3 & 16 & 10.600 & 236 & 1 & 10 & 23 & 10.599 & -259 \\
\hline 1 & 4 & 16 & 9.000 & 203 & 1 & 7 & 20 & 10.600 & -256 \\
\hline 2 & 2 & 9 & 7.184 & 171 & 2 & 7 & 20 & 10.600 & -200 \\
\hline 1 & 2 & 13 & 10.600 & 198 & 2 & 13 & 20 & 7.184 & -170 \\
\hline 1 & 5 & 11 & 4.500 & 147 & 1 & 7 & 21 & 14.368 & -225 \\
\hline 1 & 8 & 13 & 7.184 & 168 & 1 & 14 & 21 & 7.184 & -166 \\
\hline 1 & 21 & 28 & 7.184 & 164 & 1 & 22 & 26 & 12.070 & -196 \\
\hline 2 & 3 & 10 & 7.184 & 162 & 1 & 13 & 19 & 4.500 & -136 \\
\hline 1 & 15 & 19 & 12.070 & 195 & 2 & 16 & 23 & 7.184 & -154 \\
\hline 1 & 2 & 16 & 14.368 & 207 & 1 & 22 & 27 & 7.184 & -154 \\
\hline 1 & 5 & 16 & 10.600 & 178 & 1 & 13 & 26 & 10.600 & -176 \\
\hline 1 & 14 & 19 & 7.184 & 147 & 1 & 13 & 21 & 12.070 & -182 \\
\hline 2 & 20 & 27 & 7.184 & 146 & 1 & 15 & 23 & 12.070 & -182 \\
\hline
\end{tabular}

0 of 6001 and 2 Axis Measurements exceed the Planar Allowable Deviation.

The following data are an estimate of the CMM planar squareness errors:

The indicated XY plane squareness is -0.3 ( -0.07 arcseconds).

* May be affected by yaw, pitch, roll, and straightness of the included axes. 
LDDM Data Corrected for point-to-point and squareness errors. Both positions used for the analysis. Inspected by XXX Department XXX Inspection Date: 01-25-1996

The distances are in inches and deviations in microinches.

Spatial Data Performance Specification $=+/-(0.00035$ inch $+30 \mathrm{ppm})$

Inch Groups

Number measured distances

Average absolute deviation

Average deviation

Std dev over work zone

Std dev of multiple runs

Radial bias of standard

Std dev of the standard

Uncertainty of single run

Uncertainty of three runs

Allowable deviation

$\begin{array}{rrrrrrrr}\frac{\leq 6}{80} & \frac{6-10}{94} & \frac{10-12}{78} & \frac{1214}{68} & \frac{14-17}{88} & \frac{1719}{82} & \frac{1924}{78} & \frac{24}{32} \\ 40 & 85 & 71 & 84 & 68 & 72 & 67 & 65 \\ 5 & -0 & -8 & -5 & -13 & 5 & -1 & 1 \\ 53 & 101 & 93 & 101 & 88 & 88 & 84 & 83 \\ 34 & 38 & 38 & 38 & 38 & 39 & 38 & 42 \\ 6 & 6 & 7 & 7 & 8 & 8 & 9 & 10 \\ 17 & 19 & 22 & 23 & 25 & 28 & 30 & 34 \\ 149 & 274 & 247 & 275 & 237 & 243 & 232 & 233 \\ 138 & 267 & 239 & 267 & 229 & 235 & 224 & 222 \\ 485 & 566 & 668 & 712 & 782 & 872 & 922 & 1074\end{array}$

These data are the 15 most positive and 15 most negative deviations with their ball plate position, sphere pair and nominal distance; respectively ranked as a percentage of the Spatial allowable deviation.

\begin{tabular}{|c|c|c|c|c|c|c|c|c|c|}
\hline Position & \multicolumn{2}{|c|}{ Spheres } & Distance & Deviation & Position & \multicolumn{2}{|c|}{ Spheres } & Distance & Deviation \\
\hline 1 & 4 & 10 & 4.500 & 179 & 1 & 16 & 23 & 7.184 & -252 \\
\hline 1 & 3 & 10 & 7.184 & 204 & 1 & 13 & 20 & 7.184 & -233 \\
\hline 1 & 3 & 16 & 10.600 & 236 & 1 & 10 & 23 & 10.599 & -259 \\
\hline 1 & 4 & 16 & 9.000 & 203 & 1 & 7 & 20 & 10.600 & -256 \\
\hline 2 & 2 & 9 & 7.184 & 171 & 2 & 13 & 20 & 7.184 & -170 \\
\hline 1 & 5 & 11 & 4.500 & 147 & 2 & 7 & 20 & 10.600 & -200 \\
\hline 1 & 8 & 13 & 7.184 & 168 & 1 & 14 & 21 & 7.184 & -166 \\
\hline 1 & 2 & 13 & 10.600 & 198 & 1 & 7 & 21 & 14.368 & -225 \\
\hline 1 & 21 & 28 & 7.184 & 164 & 1 & 13 & 19 & 4.500 & -136 \\
\hline 2 & 3 & 10 & 7.184 & 162 & 1 & 22 & 26 & 12.070 & -196 \\
\hline 1 & 15 & 19 & 12.070 & 195 & 2 & 16 & 23 & 7.184 & -154 \\
\hline 1 & 5 & 16 & 10.600 & 178 & 1 & 22 & 27 & 7.184 & -154 \\
\hline 1 & 2 & 16 & 14.368 & 207 & 1 & 13 & 26 & 10.600 & -176 \\
\hline 1 & 14 & 19 & 7.184 & 147 & 1 & 13 & 21 & 12.070 & -182 \\
\hline 2 & 20 & 27 & 7.184 & 146 & 1 & 15 & 23 & 12.070 & -182 \\
\hline
\end{tabular}

0 of 600 Total Radial Measurements exceed the Spatial Allowable Deviation. 